Article

\title{
Performance Assessment Model for Municipal Solid Waste Management Systems: Development and Implementation
}

\author{
Hatem Abdulaziz AlHumid ${ }^{1}$, Husnain Haider ${ }^{2, *}$, Saleem S. AlSaleem ${ }^{2}{ }^{(}$, Majed Alinizzi ${ }^{2}$, \\ Md. Shafiquzaman ${ }^{2}\left(\mathbb{D}\right.$ and Rehan Sadiq ${ }^{3}$ \\ 1 Project Management Department, Municipality of Unayzah, Unayzah, Qassim 56219, Saudi Arabia; \\ hah0770@hotmail.com \\ 2 Civil Engineering Department, College of Engineering, Qassim University, Buraydah, Qassim 52571, \\ Saudi Arabia; alsaleem@qec.edu.sa (S.S.A.); alinizzi@qec.edu.sa (M.A.); shafiq@qec.edu.sa (M.S.) \\ 3 School of Engineering, University of British Columbia (Okanagan), Kelowna, BC V1V 1V7, Canada; \\ rehan.sadiq@ubc.ca \\ * Correspondence: husnain@qec.edu.sa; Tel: +966-500-574-640
}

Received: 8 January 2019; Accepted: 5 February 2019; Published: 10 February 2019

\begin{abstract}
Most of the municipalities in the Gulf region are facing performance-related issues in their municipal solid waste management (MSWM) systems. They lack a deliberate inter-municipality benchmarking processes. Instead of identifying the performance gaps for their key components (e.g., personnel productivity, operational reliability, etc.) and adopt proactive measures, the municipalities primarily rely on an efficient emergency response. A novel hierarchical modeling framework, based on deductive reasoning, is developed for the performance assessment of MSWM systems. Fuzzy rule-based modeling using Simulink-MATLAB was used for performance inferencing at different levels, i.e., component, sub-components, etc. The model is capable of handling the inherent uncertainties due to limited data and an imprecise knowledge base. The model's outcomes can exclusively assist the managers working at different levels of organizational hierarchy for effective decision-making. Performance of the key components assists the senior management in assessing the overall compliance level of performance objectives. Subsequently, operations management can home in the sub-components to acquire useful information for intra-municipality performance management. Meanwhile, individual indicators are useful for inter-municipality benchmarking. The model has been implemented on two municipalities operating in Qassim Region, Saudi Arabia. The results demonstrate the model's pragmatism for continuous performance improvement of MSWM systems in the country and elsewhere.
\end{abstract}

Keywords: solid waste management; performance assessment; fuzzy rule-based modeling; performance indicators; Simulink MATLAB

\section{Introduction}

Municipal solid waste generation rate is increasing around the world due to population growth, changing lifestyles of modern societies, and increased use of hard-to-decompose materials. As of 2016, the global average municipal waste generation rate was $0.74 \mathrm{~kg} /$ capita-day which is expected to be $1.26 \mathrm{~kg} /$ capita-day by 2050 [1]. Besides the difficulties in providing a high level of service (LOS) to the public at low cost rates, municipalities are facing challenges to meet the sustainable development goals of 21st century, such as integrated waste management and zero waste management. Similar to other public utilities (e.g., water, roads, electricity, etc.), municipal solid waste management (MSWM) systems also need to improve the performance of their key components, including public service and 
participation (PSP) [2-4], personnel adequacy and wellbeing (PAW) [2-4], environmental endurance (ENE) [5,6], physical assets efficacy (PAE) [2,6], operational reliability (OPR) [3,4,6], sustainability compliance (SSC) [6], and economic and financial viability (EFV) [3]. The performance of each of these key components can be evaluated with the help of suitable performance indicators (PIs).

Sequeiros [2] evaluated ten MSWM systems using 39 PIs in four European countries, including Portugal, England, Italy, and the Netherlands. They included three PIs in PSP, five in PAW, five PIs in EFV, nine in PAE, fourteen in OPR, and three PIs in the key component of ENE. Armijo et al. [3] identified and applied eighteen PIs to improve the performance of MSWM systems in Mexico covering the key components of PSP, PAW, OPR, and EVF. Byamba and Ishikawa [4] grouped nine PIs under the components of PSP, OPR, and PAW for assessing the performance of MSWM systems operating in six districts of Mongolia. Rigamonti et al. [5] developed three PIs to evaluate economic and environmental sustainability of MSWM systems serving four provinces of Lombardia region in Italy. Zaman [6] developed an extensive set of PIs for zero waste management, primarily covering ENE, PAE, OPR, and SSC, in Australia.

Improving the efficacy of MSWM systems has been recognized as one of the primary objectives in recent sustainable development declarations, e.g., United Nations 2030 Agenda for Sustainable Development and the Kingdom of Saudi Arabia (KSA) vision for 2030 [7,8]. While existing situation in developing world and the gulf countries needs serious efforts to achieve these objectives, the first steps towards sustainability of MSWM systems is to assess their existing performance with the help of a well-structured (which can deal with the issues related to data inadequacies and absence of benchmarks) and comprehensive (which can cover all the above key components) performance assessment model.

PIs are derived from system parameters (i.e., data variables) and inform about the status of achievement of an activity, e.g., "waste production per capita per day" and "percentage of customers not satisfied with waste management service." PIs are the primary inputs to a conventional performance benchmarking process where the participating municipalities detect their underperforming key components through cross-comparison with other municipalities operating in the region that possess similar demographic, geographic, environmental, and financial settings [9]. Establishing benchmarks in the absence of an ongoing performance benchmarking process is a challenge for the municipalities in KSA.

In conventional benchmarking process, either the individual PIs are compared or their normalized scores are aggregated to assess and compare the performance of the key components [10]. Information obtained from inter-municipality benchmarking, performed at local, regional, national, and global levels, provide useful information to the top-level management of the municipality for holistic planning of available resources [11]. Operations managers practically develop performance action plans and hold an interest in the performance of underlying processes (or sub-components) in each key component $[12,13]$. The municipalities should have a well-structured intra-municipality performance assessment setup through which they can home in on the lagging sub-components (e.g., staffing level and productivity ratio to assess personnel adequacy) and finally identify the PIs (e.g., employees per ton of daily waste generated and number of collection staff to calculate staffing level) for effective decision-making. Aggregating several PIs at the component level may come out to be a sidestep approach by neglecting the underlying processes and the findings are primarily useful at the regional level decision-making.

Literature on performance assessment of MSWM systems is scarcer as compared to other infrastructure facilities. A detailed literature review of performance assessment models for MSWM systems is out-of-scope of this research. Some relevant studies are briefly outlined here. Recently, Coelho et al. [14] carried out a detailed review of different applications of multicriteria decision-making (MCDM) in waste management. According to this review, most of the studies addressed landfill location selection problem [15,16], assessment of social and environmental impacts of different waste treatment technologies [14], and selection of types of waste treatment facilities [17]. 
Mendes et al. [18] applied PIs to evaluate the performance, using a simple weighted sum approach of waste management systems in regions with extensive seasonal tourism activities in Portugal. Sequeiros [2] calculated thirty-nine PIs to benchmark, based on simple cross-comparison, ten urban waste services in Portugal. Armijo et al. [3] used eighteen PIs to develop a driving force-pressure-state-impact-response model for performance improvement of waste management programs. Simple addition was used to assess the performance (response) for each PI.

In some of these studies, the performance of a specific component, based on data obtained from a large number of municipalities, was assessed using a set of a few PIs for regional or global comparison [18-29]. Guerrini et al. [19] evaluated performance of forty municipalities in Verona, Italy, using non-parametric method based on extensive data requirements. Căilean and Teodosiu [20] evaluated the evolution process of sustainable development of MSWM systems between 2004 and 2013 in Romania. Anestina et al. [21] assessed economic productivity performance of 30 companies that adopted a private sector participation approach for solid waste management in Nigeria. Huang et al. [22] performed performance assessment of 307 MSWM systems in Taiwan using only five key indicators. Lohri et al. [23] evaluated financial sustainability, using cost-revenue analysis, of MSWM systems in Ethiopia. Recently, Abbondanza and Souza [24] estimated the e-waste generation from the residential sector in Brazil.

In contrast, an overwhelming number of PIs were developed to achieve sustainability objectives for zero waste management systems in developed countries [6,25]. Zero waste management is a relatively more recent concept in which waste is considered as a resource produced at an intermediate phase of the resource consumption process [6]. The concept requires several PIs for detailed evaluation of different processes, e.g., amount and frequency of each type of organic and inorganic components of waste, etc. Such a notion is not valid for the municipalities struggling in gathering basic data for performance assessment, and thus, it can be difficult to adopt for assessing the performance of MSWM.

In past studies, either fewer PIs were used to cover a specific aspect of MSWM systems or extensive data sets of past performance were used for large number of participating municipalities. Moreover, uncertainties due to observational errors and limited data were not taken into account. Defining benchmarks to initiate the performance assessment of MSWM systems in KSA, and other countries with a similar situation, is the first challenge. For the quantitative PIs that are supposed to be equal or less than a certain standard value, benchmarks can be established as the desired standards, e.g., noise levels, water quality, ambient air quality, etc. [26]. The problem is more significant in the case of qualitative PIs or newly developed PIs without any past information. Second, establishing desired LOS based on expert knowledge, indigenous know-how, and available literature leads to several possible uncertainties in the performance assessment process, such as vagueness in expert opinion, limited knowledge, variations in data due to limited number of measurements, and possible equipment and human errors [13,27].

To the best of authors knowledge, there is no existing performance assessment model that can answer the following questions: (i) How to initiate the performance assessment process for MSWM systems in the absence of extensive past data? (ii) How to use PIs for effective decision-making at different levels (top and operational management) of the organizational hierarchy? (iii) How to address different uncertainties, associated to data limitations, measurement errors, vagueness in expert opinion, and imprecision in indigenous knowledge, exist in the performance assessment process?

Performance benchmarking of MSWM systems has not been fully established in many countries so far, including Saudi Arabia and Gulf region. The main objective of this research is to develop a performance assessment model for municipal solid waste management systems (PAM-SWM) to address the above stated issues for sustainability of MSWM systems in the Gulf region. PAM-SWM provides a platform to the municipality manager for performance assessment in the absence of an existing benchmarking process. The outcomes of the proposed model can be simultaneously used for inter-municipality benchmarking and intra-municipality performance management. 


\section{Materials and Methods}

\subsection{Performance Assessment Criteria}

A hierarchical-based top-down model is developed to assess the performance of seven key components, including the PSP, PAW, PAE, OPR, ENE, SSC, and EFV. These key components were identified based on the most commonly used classifications in past studies as described in the beginning of the Introduction section. Details of model's structure are provided in the Section 4. Performance assessment criteria consists of performance objectives of the key components at the top of the hierarchy, followed by performance attributes of subcomponents at level 1 and level 2. At the bottom of the hierarchy, the data variables are used to calculate the PIs. The PIs are the main building blocks, which provide inputs to the upper levels of hierarchy. Most of the PIs have been selected through an exhaustive literature review including the studies reviewed in Introduction section. In present study, performance objectives, performance attributes (PAs), and the PIs are developed based on their indigenous relevance for performance assessment of MSWM systems in the KSA.

The performance assessment criteria developed in the present research are itemized in Table 1. Each level of parent-child-hierarchy corresponds to a specific generation. The first four columns of Table 1 present the four generations of performance assessment hierarchy for all the seven key components, including performance objectives, performance attributes (for both the subcomponents level-1 and level-2). Basic inputs consisting of data variables and the decision variables are given in the fifth column, while the possible improvement actions are listed in the last column of Table 1. The data variables will be obtained from the participating municipalities for a given assessment period, i.e., preferably one year. For example, the data variables for the PI of "employees per ton of daily waste generated" (PE1) are "total number of full-time employees" and "ton of daily waste generated." The decision variables could be the numerators, denominators, or both, e.g., in the case of PE1, both the variables are decision variables that can be improved.

The approach developed in this study will systematically facilitate the decision-makers working at various levels in the organizational hierarchy structure of MSWM systems. Top-level managers and policymakers are more concerned with the compliance and non-compliance of performance objectives to assess the overall performance of their MSWM systems to obtain financial approvals from government or to establish a rationale for overall performance improvement [28]. Operational managers will be interested in the performance of their respective sub-component, e.g., landfill manager, operation and maintenance (O\&M) manager, transportation manager, manager of cleaning, environmental and chemical laboratory in charge, etc. In the remaining text, all the performance factors, i.e., objectives, attributes, and indicators, are designated as italics. While the PIs are labeled with their corresponding code stated in the fourth column of Table 1 . The performance assessment criteria are discussed in the following sub-sections.

\subsubsection{Public Service and Participation (PSP)}

Two sub-components at level-1, including "quality of service" and "level of public participation" assesses the key component of "Public Service and Participation" (Table 1). The former counts the effectiveness of three PIs which are "solid waste production per capita" (PU1), "coverage of collection services" (PU2), and the "persons not satisfied with the waste management services" (PU3). The first PI indirectly reflects the success of sustainable waste practices in the area, i.e., high per capita waste generation shows that the public is not fully informed about these practices or a government's vision towards waste management. The second PI conveys the evidence about the part of the service area not being covered by the municipality. 
Table 1. Performance objectives, performance measures (PMs), performance indicators (PIs), and data variables.

\begin{tabular}{|c|c|c|c|c|c|}
\hline $\begin{array}{c}\text { Generation } \\
\text { 1-Component } \\
\text { (Performance } \\
\text { Objectives) } \\
\end{array}$ & $\begin{array}{l}\text { Generation } \\
\text { 2-Sub-Components } \\
\text { (Level 1) (PM) }\end{array}$ & $\begin{array}{l}\text { Generation } \\
\text { 3-Sub-Components } \\
\text { (Level 2) (PM) }\end{array}$ & Generation 4-Performance Indicators (PIs) & Data Variables/Decision Variables ${ }^{1}$ & Possible Improvement Actions \\
\hline $\begin{array}{l}\mathbf{X}_{1}-\text { Public Service and } \\
\text { Participation (PSP) }\end{array}$ & $\begin{array}{l}\mathbf{X}_{1,1} \text {-Quality of Service } \\
\mathbf{X}_{1,2} \text {-Level of Public } \\
\text { Participation }\end{array}$ & - & 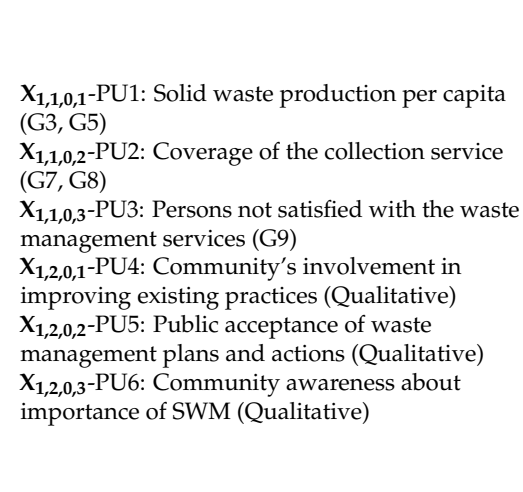 & $\begin{array}{l}\text { G3: Total population in service area } \\
\text { G5: Average weight of solid waste per } \\
\text { day (D) } \\
\text { G7: Total area under the jurisdiction of } \\
\text { the municipality }\left(\mathrm{km}^{2}\right) \\
\text { G8: Area served by the municipality } \\
\left(\mathrm{km}^{2}\right)(\mathrm{D}) \\
\text { G9: Total number of reported complaints } \\
\text { (written or telephonic) (D) }\end{array}$ & $\begin{array}{l}\text { - Average weight of solid waste } \\
\text { should be reduced by promoting } \\
\text { recycling and reuse practices by } \\
\text { implementing two-bin and } \\
\text { three-bin systems, i.e., reducing G5 } \\
\text { - Increasing coverage of service area, } \\
\text { i.e., G8 } \\
\text { - Prompt response and satisfactory } \\
\text { resolution of reported complaints, } \\
\text { i.e., G9 } \\
\text { Involving community in the } \\
\text { decision-making process, i.e., } \\
\text { increasing PU4 and PU5 } \\
\text { Increasing awareness among public } \\
\text { through traditional and social } \\
\text { media, i.e., improving PU6 }\end{array}$ \\
\hline $\begin{array}{c}\mathbf{X}_{2} \text {-Personnel adequacy } \\
\text { and wellbeing (PAW) }\end{array}$ & $\begin{array}{l}\mathbf{X}_{2,1} \text {-Personnel Adequacy } \\
\mathbf{X}_{2,2} \text {-Wellbeing and } \\
\text { workplace performance }\end{array}$ & $\begin{array}{l}\mathbf{X}_{2,1,1} \text {-Staffing level } \\
\mathbf{X}_{2,1,2} \text {-Productivity ratio }\end{array}$ & 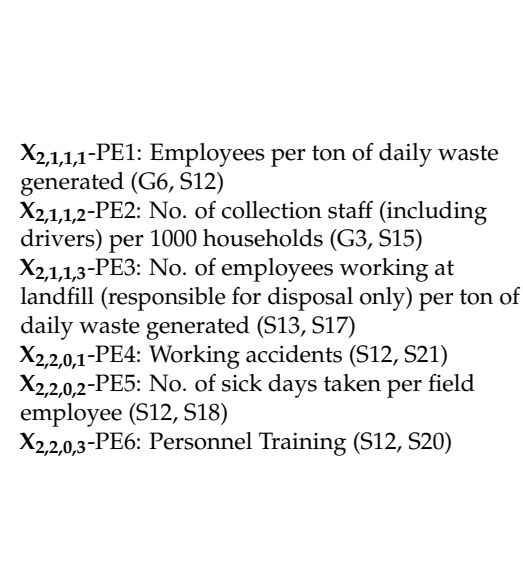 & $\begin{array}{l}\text { G3: Total population in service area } \\
\text { G6: Total weight of waste (D) } \\
\text { S12: Total number of full-time } \\
\text { employees (D) } \\
\text { S13: Weight in ton of average daily } \\
\text { waste generated (D) } \\
\text { S15: No. of collection staff (D) } \\
\text { S17: No. of employees working at } \\
\text { landfill (responsible for disposal only) } \\
\text { (D) } \\
\text { S18: No. of sick leaves taken by the } \\
\text { employees (D) } \\
\text { S20: Number of annual hours for } \\
\text { personnel training (D) } \\
\text { S21: Number of working hours lost due } \\
\text { to field accidents in a year (D) }\end{array}$ & 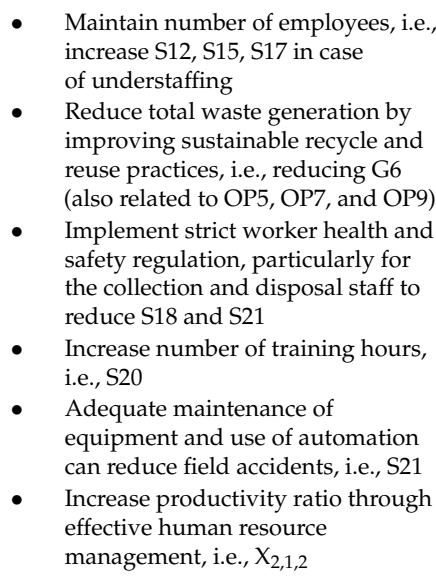 \\
\hline
\end{tabular}


Table 1. Cont

\begin{tabular}{|c|c|c|c|c|c|}
\hline $\begin{array}{c}\text { Generation } \\
\text { 1-Component } \\
\text { (Performance } \\
\text { Objectives) } \\
\end{array}$ & $\begin{array}{c}\text { Generation } \\
\text { 2-Sub-Components } \\
\text { (Level 1) (PM) }\end{array}$ & $\begin{array}{c}\text { Generation } \\
\text { 3-Sub-Components } \\
\text { (Level 2) (PM) }\end{array}$ & Generation 4-Performance Indicators (PIs) & Data Variables/Decision Variables ${ }^{1}$ & Possible Improvement Actions \\
\hline $\begin{array}{l}\mathrm{X}_{3} \text {-Environmental } \\
\text { Endurance (ENE) }\end{array}$ & $\begin{array}{l}\mathbf{X}_{3,1} \text {-Condition of } \\
\text { environmental aesthetics } \\
\mathbf{X}_{3,2} \text {-Condition of } \\
\text { geo-environment } \\
\mathbf{X}_{3,3} \text {-Leachate treatment } \\
\text { efficacy }\end{array}$ & $\begin{array}{l}\mathbf{X}_{3,2,1} \text {-Impacts of physical } \\
\text { parameters } \\
\mathbf{X}_{3,2,2} \text {-Impacts of } \\
\text { biochemical parameters } \\
\mathbf{X}_{3,2,3} \text {-Impacts of chemical } \\
\text { parameters }\end{array}$ & $\begin{array}{l}\mathbf{X}_{3,1,0,1} \text {-EN1: Visual impact } \\
\mathbf{X}_{3,1,0,2} \text {-EN2: Odor impact } \\
\mathbf{X}_{3,2,1} \text {-EN3: Temperature of leachate (E62) } \\
\mathbf{X}_{3,2,1,2} \text {-EM4: (TDS) in leachate (E62) } \\
\mathbf{X}_{3,2,1,3} \text {-EN5: Total suspended solid (TSS) (E70) } \\
\mathbf{X}_{3,2,2,1} \text {-EN6: BOD in leachate (E71) } \\
\mathbf{X}_{3,2,2,2} \text {-EN7: COD in leachate (E72) } \\
\mathbf{X}_{3,2,2,3} \text {-EN8: BOD/COD Ratio (E71) (E72) } \\
\mathbf{X}_{3,2,3,1} \text {-EN9: Nitrates (NO3) (E68) } \\
\mathbf{X}_{3,2,3,2} \text {-EN10: Phosphorus concentration in } \\
\text { leachate (E76) } \\
\mathbf{X}_{3,2,2,3,3} \text {-EN11: ammonia concentration in } \\
\text { leachate (E78) }\end{array}$ & $\begin{array}{l}\text { E62: Temperature of leachate }\left({ }^{\circ} \mathrm{C}\right) \\
\text { E68: Nitrates }(\mathrm{NO} 3) \text { in leachate }(\mathrm{mg} / \mathrm{L}) \\
\text { E70: TDS in leachate }(\mathrm{mg} / \mathrm{L}) \\
\text { E71: BOD in leachate }(\mathrm{mg} / \mathrm{L}) \\
\text { E72: COD in leachate }(\mathrm{mg} / \mathrm{L}) \\
\text { E76: (PO4) phosphate concentration in } \\
\text { leachate }(\mathrm{mg} / \mathrm{L}) \\
\text { E78: Concentration of ammonia gas in } \\
\text { landfill }(\mathrm{mg} / \mathrm{L}) \\
\text { E80: }(\mathrm{TSS}) \text { Total suspended solid }(\mathrm{mg} / \mathrm{L})\end{array}$ & $\begin{array}{l}\text { - Increase plantation around the } \\
\text { landfill site to reduce visual impact } \\
\text { i.e., EN1 } \\
\text { - Use best housekeeping practices to } \\
\text { control odor, i.e., EN2 } \\
\text { - Install an efficient leachate } \\
\text { treatment facility, i.e., improve } X_{3,3} \\
\text { - Efficient recovery of recyclables and } \\
\text { reusable to improve leachate } \\
\text { quality, i.e., reduced E68, E70, E71, } \\
\text { E72, E76, E78, E80, and the cost of } \\
\text { leachate treatment. }\end{array}$ \\
\hline $\begin{array}{l}\text { X-Physical Assets } \\
\text { Efficacy (PAE) }\end{array}$ & $\begin{array}{l}\mathbf{X}_{\mathbf{4}, 1} \text {-Self-sufficiency of } \\
\text { Physical Systems } \\
\mathbf{X}_{\mathbf{4}, 2} \text {-Efficiency of physical } \\
\text { systems }\end{array}$ & - & $\begin{array}{l}\mathbf{X}_{4,1,0,0}-\mathrm{PH} 1: \text { Presence of material recovery } \\
\text { facility } \\
\mathbf{X}_{\mathbf{4}, 1,1,0,2} \text {-PH2: Lack of appropriate waste recycling } \\
\text { facilities } \\
\mathbf{X}_{\mathbf{4}, 2,0,1} \text {-PH3: Equipment cleaning frequency } \\
\text { (P56) } \\
\mathbf{X}_{4,2,0,2} \text {-PH4: Inefficient waste collection vehicles } \\
\text { (P53) (P58) }\end{array}$ & $\begin{array}{l}\text { P56: Number of times equipment } \\
\text { cleaned during a year (D) } \\
\text { P53: Inefficient waste collection } \\
\text { equipment (D) } \\
\text { P58: Total number of vehicles }\end{array}$ & $\begin{array}{l}\text { - Install a state-of-the-art material } \\
\text { - } \quad \text { Incovery facility (MRF), i.e., PH1 } \\
\text { frequency, i.e., P56 } \\
\text { - } \\
\text { Repair and replace inefficient waste } \\
\text { collection equipment, i.e., } \\
\text { reduce P53. }\end{array}$ \\
\hline $\begin{array}{c}\mathrm{X}_{5} \text {-Operational Reliability } \\
\text { (OPR) }\end{array}$ & $\begin{array}{l}\mathbf{X}_{5,1} \text {-Efficacy of waste } \\
\text { generation, separation, } \\
\text { and collection systems } \\
\mathbf{X}_{5,2} \text {-Efficacy of waste } \\
\text { recycling, and disposal } \\
\text { systems }\end{array}$ & $\begin{array}{l}\mathbf{X}_{5,1,1} \text {-Effectiveness of } \\
\text { waste classification } \\
\text { mechanism } \\
\mathbf{X}_{5,1,2} \text {-Waste Handling and } \\
\text { Separation Rate } \\
\mathbf{X}_{5,1,3} \text {-Collection/Transfer } \\
\text { and Transport Rate } \\
\mathbf{X}_{5,2,1} \text {-Recycling Efficiency } \\
\mathbf{X}_{5,2,2} \text {-Landfill and } \\
\text { Disposal Efficiency }\end{array}$ & 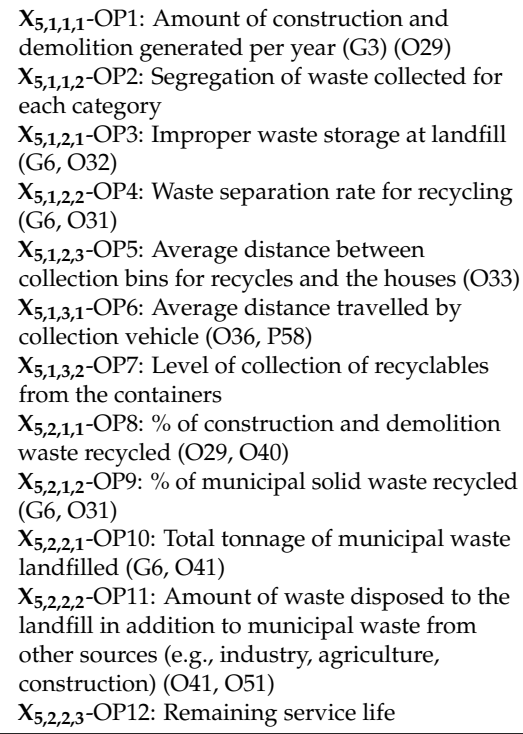 & $\begin{array}{l}\text { G3: Total population in service area } \\
\text { G6: Total weight of waste } \\
\text { O29: Daily weight of construction and } \\
\text { demolition generated } \\
\text { O31: Amount of recycled waste per day } \\
\text { (D) } \\
\text { O32: Amount of Improper waste storage } \\
\text { (D) } \\
\text { O33: Average distance between the } \\
\text { houses and the collection bin for } \\
\text { recyclables (D) } \\
\text { O36: Average daily distance travelled in } \\
\text { Km by the collector trucks (D) } \\
\text { O40: The weight of construction and } \\
\text { demolition waste recycled } \\
\text { O41: Total tonnage of municipal waste } \\
\text { landfilled } \\
\text { O51: The tonnage of waste disposed of } \\
\text { to landfill in addition to Municipal (D) } \\
\text { P58: Total number of vehicles }\end{array}$ & 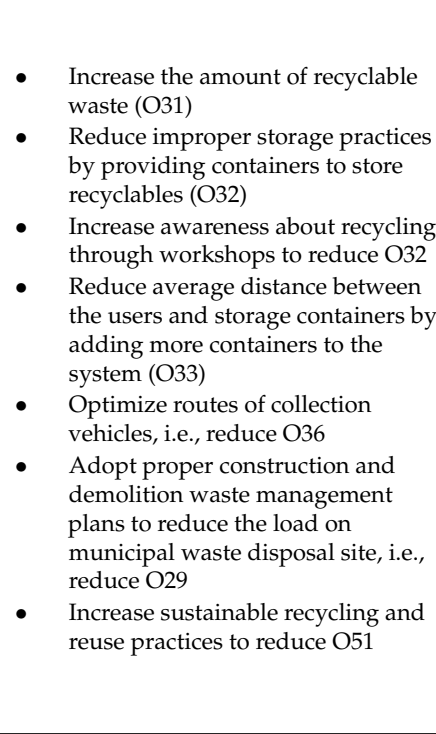 \\
\hline
\end{tabular}


Table 1. Cont

\begin{tabular}{|c|c|c|c|c|c|}
\hline $\begin{array}{c}\text { Generation } \\
\text { 1-Component } \\
\text { (Performance } \\
\text { Objectives) }\end{array}$ & $\begin{array}{c}\text { Generation } \\
\text { 2-Sub-Components } \\
\text { (Level 1) (PM) }\end{array}$ & $\begin{array}{c}\text { Generation } \\
\text { 3-Sub-Components } \\
\text { (Level 2) (PM) }\end{array}$ & Generation 4-Performance Indicators (PIs) & Data Variables/Decision Variables ${ }^{1}$ & Possible Improvement Actions \\
\hline $\begin{array}{l}\mathbf{X}_{6} \text {-Sustainability } \\
\text { Compliance (SSC) }\end{array}$ & & & $\begin{array}{l}\mathbf{X}_{6,0,0,1}-\text { SU1: Rate of increase total amount of } \\
\text { MSW generation (E85) (E86) } \\
\mathbf{X}_{6,0,0,2} \text {-SU2: Application of life cycle costing } \\
\text { (LCC) and life cycle assessment (LCA) } \\
\mathbf{X}_{6,0,0,3} \text {-SU3: Treatment facilities dynamics }\end{array}$ & $\begin{array}{l}\text { E85: Amount of MSW generated during } \\
\text { a past year, i.e., } 2016 \\
\text { E86: Amount of MSW generated during } \\
\text { a year before the past year, e.g. } 2015\end{array}$ & $\begin{array}{l}\text { - Introduce and implement } \\
\text { sustainable recycling and reuse } \\
\text { practices to reduce E85 } \\
\text { Conduct detailed LCC and LCA } \\
\text { studies to improve overall } \\
\text { sustainability of municipal solid } \\
\text { waste management system in the } \\
\text { study area, increase SU2 }\end{array}$ \\
\hline $\begin{array}{c}\mathbf{X}_{7} \text {-Economic and } \\
\text { Financial Viability (EFV) }\end{array}$ & & & $\begin{array}{l}\mathbf{X}_{7,0,0,1}-\mathrm{EF} 1 \text { : Collection cost/ton of waste } \\
\text { generated (G6) (E92) } \\
\mathbf{X}_{7,0,0,2} \text {-EF2: Cost of municipal wastes disposal } \\
\text { per metric ton (O51) (E90) } \\
\mathbf{X}_{7,0,0,3} \text {-EF3: Recycling cost/ton of waste } \\
\text { generated (G6) (E95) }\end{array}$ & $\begin{array}{l}\text { G6: Total weight of waste } \\
\text { O51: The tonnage of waste disposed of } \\
\text { to landfill in addition to Municipal } \\
\text { E90: Operational cost of landfill and } \\
\text { MRF during an assessment period } \\
\text { E92: Total collection cost incurred } \\
\text { E95: Weight of recycled solid waste }\end{array}$ & $\begin{array}{l}\text { - Increase recycling and reuse of } \\
\text { waste to reduce total weight of } \\
\text { weight and consequently reduce } \\
\text { EF1 and EF2 } \\
\text { EF3 will increase with installation } \\
\text { of MRF, some cost should be } \\
\text { recovered from the community, i.e., } \\
\text { improved level of public } \\
\text { participation }\left(\mathrm{X}_{1,2}\right) \text { can help to } \\
\text { achieve this objective } \\
\text { Willingness to pay surveys can be } \\
\text { conducted to evaluate the feasibility } \\
\text { of generating revenues from solid } \\
\text { waste collection service }\end{array}$ \\
\hline
\end{tabular}

\footnotetext{
${ }^{1}$ The letters used for data/decision variables are: A—water resources and environmental data, B-Personnel data, C-Physical assets data, D-Operational and monitoring data,
}

E-Demographic data, F-Data related to customers services, G-Financial data. ${ }^{2}$ The data used to calculate the PIs in given within brackets at the end of each PI. 
Customers satisfaction depends on the gap between the level of service (LOS) provided by the municipality and the customers' expected LOS. It also depends on a certain level of acceptance of the performance gap subject to the cost being paid by the customers for a given LOS. The trust of the customers, i.e., built on the basis of long-term performance of the municipality, also dictates the level of customer satisfaction [29]. LOS can be assessed through interview surveys, but the relationship between the customer and the service provider in the Gulf is exclusive as MSWM is a public service (without any cost) instead being a sold product. The term "public" seems to be more coherent than the conventional terms used, i.e., "customers." The last indicator (PU3) provides the facts about complaints (both the written and oral) reported by the public in a given assessment period. If the data is available, additional sub-components at level-2 can be added to evaluate the response and resolution times of these complaints. Presently, the data is only available about the number of complaints and thus included in this sub-component level-1.

The second sub-component (level-1), "level of public participation", is assessed by encompassing three useful PIs, including "community involvement in improving existing practices" (PU4), "public acceptance of waste management plans and actions" (PU5), and "community awareness about importance of SWM" (PU6) [18] (see Table 1). Effective involvement of community in the decision-making process improves the LOS [4]. In situations where MSWM is a free service and no economic stakes of the public exist, it might be challenging to motivate a large majority of public to be involved in the improvement process of existing practices. PU4 can be enhanced by promoting awareness (PU6) about environmental consequences of not adopting sustainable practices in future through media and regular education circulars. Better situational awareness will subsequently enhance the performance level of both the PU4 and PU5. Measurability of these PIs will require a structured process of keeping the record of all the public-service provider meetings; for the moment, these PIs are qualitatively calculated based on the practical knowledge of municipality managers.

\subsubsection{Personnel Adequacy and Wellbeing (PAW)}

The key component of "personnel adequacy and wellbeing" is evaluated with the help of two level-1 sub-components, including "personnel adequacy", and "wellbeing and workplace performance".

The first sub-component level 1 is further built upon two level-2 sub-components, including "staffing level" and "staff productivity ratio". "Staffing level" is an aggregated measure of three PIs "employees per ton of daily waste generated" (PE1), "number of collection staff per 1000 households" (PE2), and "number of employees working at landfill per ton of daily waste generated" (PE3). The first PI is an overall measure of personnel adequacy and is useful for cross-comparison with other municipalities. The other two PIs in this sub-component evaluate the efficacy of personnel to perform two important elements of solid waste management, i.e., collection and disposal. In addition to collection managers and supervisors, PE2 includes the drivers (both the fulltime or part-time). In case of part-time drivers, working hours can be used to calculate the full-time equivalent (FTE) employees in addition to full time employees. Generally, there is an integrated facility at the final disposal point dealing simultaneously with MRF and landfilling operations. PE3 should be calculated for the personnel exclusively responsible for landfill operations.

It has been reported that due to better opportunities in large cities, hiring and retaining trained personnel in smaller municipalities is more challenging as compared to the large municipalities [13]. In general, different personnel might be responsible for multiple tasks, so the FTE employees should be carefully estimated, particularly for top level management who is taking part in decision-making for other utilities in a municipality. Staffing level is usually kept to a minimum in large systems to efficiently perform routine operations. This also results in a high "staff productivity ratio" (SPR) and is calculated as the ratio between "tons of solid waste generated in a year" and the "total number of FTE employees". A certain number of personnel is indispensable for any municipality to efficiently perform the routine operations. Over-hiring can result in a financial burden; thus, the overall numbers of FTE 
employs need to be optimized rationally. PAM-SWM maintains a balance between minimum "staffing level" and high "SPR", to achieve the attribute of "personnel adequacy".

The third level-1 sub-component consists of three PIs, including "working accidents during the assessment period" (PE4), "number of sick days taken per field employee" (PE5), and "personnel training hours in the assessment period" (PE6). The first two PIs measure an overall effectiveness of the health and safety culture in the municipality while training of personnel in inevitable to meet the sustainability objectives of Saudi Arabia's Vision 2030 [8].

\subsubsection{Environmental Endurance (ENE)}

The performance of the key component of "environmental endurance" is appraised from three level-1 sub-components, including "condition of environmental aesthetics," "condition of geo-environment," and "leachate treatment efficacy." The first sub-component is assessed with the help of two PIs, including "visual impact" (EN1) and "odor impact" (EN2). Movement of vehicles and dumping of waste can produce dust in the landfill area. Littering due to movement of animals and rodents can affect the visual character of the attributes of natural landscape. Landfill operations also generate various types of odorous gases, e.g., ammonia, $\mathrm{CO}$, methane, etc., which can be annoying for the public, particularly living in the nearby settlements. Proper fencing and plantation at the landfill site can reduce these impacts to a certain extent. Keeping the landfill site outside the main city is a planning measure that can minimize these impacts on the environmental aesthetics over the long-term operational phase.

Impact of leachate on geo-environment is assessed with the help of three level-2 subcomponents, including "impacts of physical parameters," "impacts of biochemical parameters" and "impacts of chemical parameters." The PIs (i.e., parameters) for which the data was available with the participating municipalities were used to evaluate these sub-components. "Temperature", "total dissolved solids (TDS)", and "total suspended solids (TSS)" were encompassed under the first sub-component as the physical parameters, i.e., EN3, EN4, and EN5. Bio-chemical parameters of leachate included "5-day biochemical oxygen demand (BOD)", "chemical oxygen demand (COD)", and the "ratio between BOD and $C O D$ " (i.e., BOD:COD), i.e., EN6, EN7, and EN8. The third sub-component was comprised of three PIs, including "nitrates" (EN9), "phosphorus" (EN10), and "ammonia" (EN11). An efficient leachate collection and treatment system is required to minimize the adverse impacts of these parameters.

All the physical, biochemical, and chemical parameters were quantitatively measured in terms of concentrations through laboratory analysis, while the aesthetic PIs were qualitatively assessed based on the expert judgment of field staff. Higher values of all these parameters were either directed toward the possibility of anaerobic conditions in the landfill, which may lead to adverse impacts on soil and groundwater, or directs towards improper planning, design, and operations of the landfill.

\subsubsection{Physical Assets Efficacy (PAE)}

Two sub-components level-1, including "self-sufficiency of physical systems" and "efficiency of physical systems" appraise the key component of "physical assets efficacy". The first sub-component consists of two PIs, including "presence of material recovery facility" (PH1) and "lack of appropriate waste recycling facilities" (PH2) (also see Table 1).

A fully automated MRF separates, processes, and stores the solid waste for remanufacturing or reprocessing with additional benefits can be obtained in terms of financial revenues and biogas production [30]. A recovery facility is more desired, particularly for the service areas with inadequate or absent source separation practices. The second PI selected under the first sub-component, i.e., (PH2), is included for smaller municipalities relying on manual recovery of recyclables in the absence of a contemporary facility. Special care is needed to reduce the risk to worker's health and safety during the manual waste separation process. Inadequate waste recovery processes (i.e., high $\mathrm{PH} 3$ ) may reduce the remaining service life of the landfill due to possible increase in the landfilling rate [31].

The performance of the second sub-component depends on "equipment cleaning frequency" (PH3) and "inefficient waste collection equipment" (PH4). Following the best practices, it is mandatory for all 
the municipalities to follow an inclusive O\&M plan for their equipment and vehicles. $\mathrm{PH} 3$ calculates the number of times an equipment is cleaned during a given assessment period while PH4 informs about the rusty and aged storage containers. A higher number of such containers may lead to both the operational difficulties (i.e., more time spent at the collection site due to handling of scruffy containers) and the nuisance to public due to blowing litter and spilling of liquid waste from such containers.

\subsubsection{Operational Reliability (OPR)}

The key component of "operational reliability" is evaluated with the help of two sub-components (level 1), including "efficacy of waste generation, separation, and collection systems", and "efficacy of waste recycling, and disposal systems".

The performance of first level 1 sub-component depends on three level 2 sub-components, i.e., "waste categorization rate," "waste handling and separation rate," and "collection/transfer and transport rate." Waste categorization rate is assessed with the help of two PIs: "amount of construction and demolition generated per year" (OP1) and "segregation of waste collected for each category" (OP2). The first PI is included in this sub-component because the municipalities are receiving construction and demolition $(C \& D)$ waste from the service areas in the absence of separate facility to deal with this recyclable waste. The entire waste received at the disposal site can be categorized by improving OP2.

The second sub-component (level 2) has been evaluated with the help of three PIs, including "discarded inorganic waste" (OP3), "waste separation rate for recycling" (OP4), and "average distance between collection bins for recycles and the houses" (OP5). OP3 consists of the percentage of total waste that can neither be recycled nor disposed of in the landfill due to its inorganic nature and can only be incinerated. OP4 reflects the level of separation of recyclables at the source. Through personal communication with the municipality personnel, it was found that some of the households separate the recyclable waste and place it next to the collection bin at the nearest collection point or outside their yards. The general public avoids walking for distances longer than 250m [32] to dispose recyclables in the community containers (which have been placed outside some central locations such as hospitals, malls, etc.); according to others not more than $60 \mathrm{~m}$ [33]. Therefore, OP5 determines the need of a two bin system for individual households.

The third sub-component level 2, under the first level 1 sub-component, contains two PIs, including "average distance travelled by collection vehicle" (OP6) and "level of collection of recyclables from the containers" (OP7). The former can facilitate for optimizing the routes of collection vehicles while later identifies the need of additional community bins.

Second sub-component level 1 has been assessed with the help of two sub-components at the second level of the hierarchy, including "recycling efficiency" and "landfill and disposal efficiency." The first level 2 sub-component consists of two PIs of "CED waste recycled" (OP8) and "municipal solid waste recycled" (OP9). The second sub-component at the same level evaluates the utilization of landfill and its remaining service life with the help of OP10, OP11, and OP12 (See Table 1).

\subsubsection{Sustainability Compliance (SSC)}

For sustainable development, through the life cycle, i.e., planning, design, operation and maintenance, and the end-of-life, a MSWM facility needs to adopt best practices [34]. Sustainability of a MSWM system depends on the level of waste recycling and reuse practices in the service area, implementation of state-of-the-art methods for sustainability assessment, and the dynamics of the waste treatment facilities. Therefore, sustainability performance component has been directly assessed from three PIs, including "annual increase in total amount of solid waste" (SU1), "level of application of life cycle costing (LCC) and life cycle assessment (LCA) tools" (SU2), and "treatment facilities dynamics" (SU3).

SU1 directs towards two important aspects: (i) possible expansions in the service area, and (ii) increasing rate of per capita waste production due to increasing affluence and technological advances. SU2 expresses the degree of sustainable practices in a municipality, such as LCC and LCA. LCC is more helpful for managing the infrastructure assets. LCA effectively assesses and mitigates the possible 
environmental impacts during all the phases of a MSWM facility, e.g., climate change, ecotoxicity, respiratory effects, etc. In past studies, integrated waste management options have been identified as the most sustainable practice for minimizing both the cost and environmental impacts, for instance, landfilling and composting alone or in combination [35].

\subsubsection{Economic and financial viability (EFV)}

The key component of "economic and financial viability" is directly derived from three PIs, including "collection cost per ton of waste generated" (EF1), "cost of municipal wastes disposal per metric ton" (EF2), and "recycling cost per ton of waste generated" (EF3). These three PIs were selected to assess the performance of this component based on availability of financial information and recognizing the privacy constraints of the participating municipalities for financial data sharing.

\subsection{Performance Assessment Model for Municipal Solid Waste Management Systems (PAM-SWM)}

The proposed methodology for the development of performance assessment model for municipal solid waste management systems (PAM-SWM) is presented in Figure 1. The step-by-step procedure of model development is given in the following sub-sections.

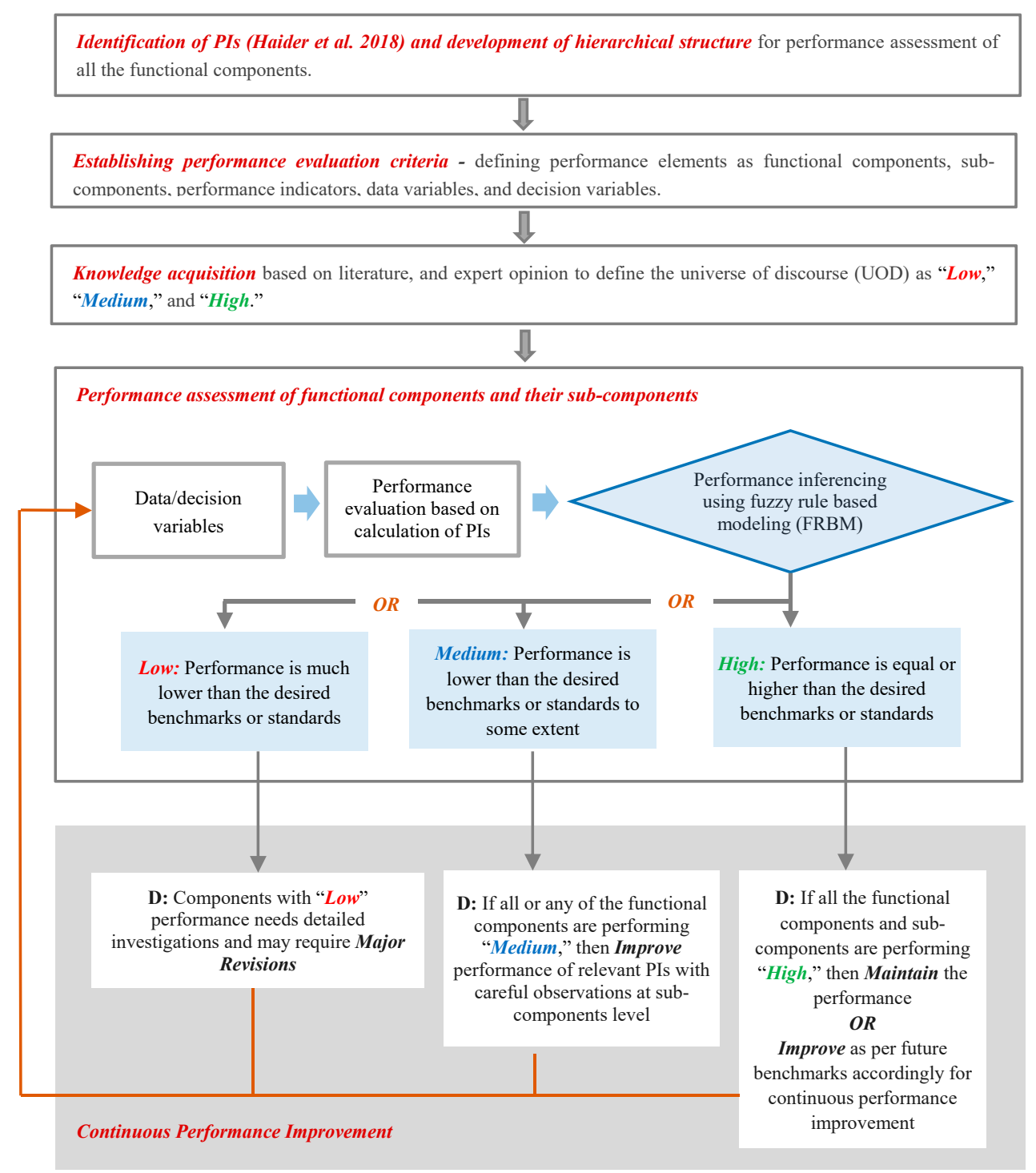

Figure 1. Conceptual model for performance assessment of municipal solid waste management (MSWM) Systems. 


\section{Step 1: Select PIs and develop a conceptual hierarchical structure}

Two approach of reasoning have been used for sustainability performance modeling, including deductive reasoning and inductive reasoning. The top-down approach is based on deductive reasoning where the experts define both the framework as well as the sustainability criteria. Inductive reasoning facilitates using the bottom-up approach in which different stakeholders provide their inputs for developing the framework and establishing the sustainability criteria [36]. In present research, the performance assessment criteria (developed in Section 2), consisting of performance objectives, performance attributes, and PIs, have been structured using the top-down approach in Figure 2.

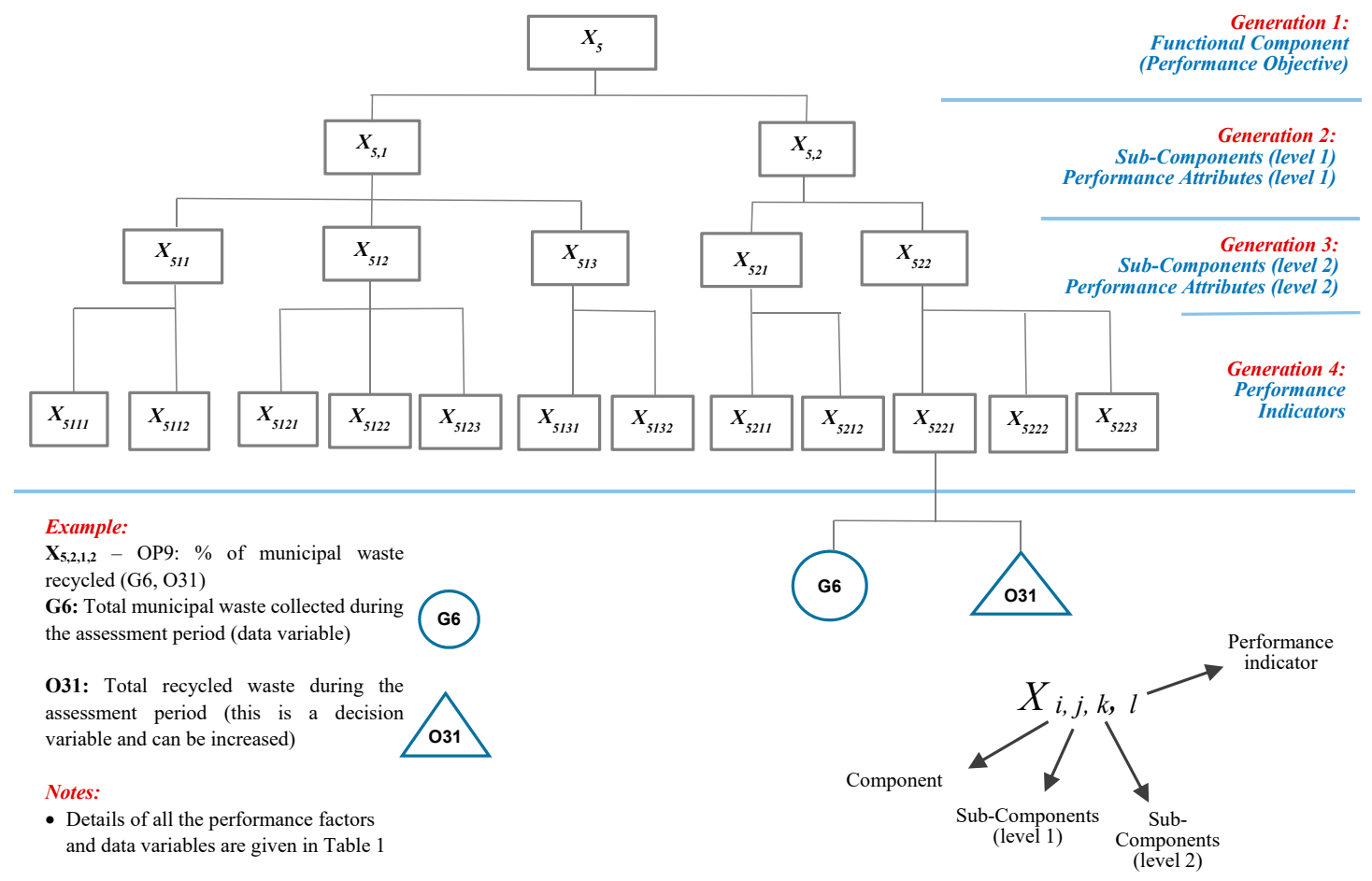

Figure 2. A conceptual hierarchical structure for the performance assessment of MSWSs: an example of the functional component of operational efficiency.

PIs were identified through an exhaustive literature review and selected through a subsequent screening process. Managers from the two participating municipalities in the Qassim province and experts from academia were involved in the selection process.

Figure 2 presents the concept of the deductive hierarchical approach used in this research to develop PAM-SWM. The concept is based on a typical "family" structure akin to a parent-child relationship. The oldest parent in the family corresponds to the main key component of MSWM. In the subsequent intermediate levels of hierarchy, sub-components are the "children" of their respective parents in the upper levels of hierarchy. PIs at the bottom of the hierarchy possess no "children" and thus are called "basic performance factors." Each family may consist of one, two, or three children, and each one of them can have children in the next generation. A parent may have a younger child in lower level of hierarchy, for instance, PIs directly input to the key components of SSC and EFV.

Each member of the family in Figure 2 is essentially a performance factor. The notation $X_{i, j, k, l}$ denotes a performance factor, where $i$ corresponds to the number of a key component (e.g., OPR, SSC, etc.), $j$ represents the number of sub-components (level 1) in the current generation, $k$ is the sub-component at level 2, and $l$ is the number of the PI in the present generation. Data variables are the inputs for calculating the PIs while one of the numerator or denominator (in the PI's formula) could be a decision variable. For example, "cost of municipal waste disposal per metric ton" (EF2) can be reduced by reducing the "waste to landfill" (O51) with increasing the "weight of recycling waste" (E95) 
(also see Table 1). Thus, both the data variables O51 and E95 are essentially the decision variables as well. Some data variables are constants during the given assessment period, such as "population" (G3), "total number of collection vehicles" (P58), etc. See column 5 of Table 1 for details about data and decision variables.

\section{Step 2: Establishing performance assessment criteria}

Performance assessment criteria established in present research has already been explained in Section 2. Different performance factors have been stated in Table 1.

\section{Step 3: Knowledge acquisition}

Data variables calculate the PIs and are listed in column 5 of Table 1. Calculated PIs needs to be compared with the desired performance levels and translated into performance scores ranging from 0 to 10 with the help of a rational universe of discourse (UOD) developed through the knowledge attained from literature and the expert judgment. UOD established for all the PIs is attached as Appendix A. Calculated values of the PIs are linguistically fuzzified as "low," "medium," and "high" against the performance scores ranges of 0 to 4,3 to 7 , and 6 to 10 . The performance objective of a key component and sub-components of the hierarchy (described in Figure 2 and Table 1) varies between 0 and 100 .

As the universe of discourse (UOD) to evaluate different performance indicators was established for the municipalities operating in Saudi Arabia, the model may need minor changes for its implementation in a different region.

\section{Step 4: Performance assessment using fuzzy rules-based modeling (FRBM)}

After establishing the UOD in Step 3, the next step in Figure 1 is performance assessment. This step begins with calculating the PIs with the help of data variable for the MSWM system being investigated. The performance of sub-components (attributes) and the key component at the top of the hierarchy are inferred using the deductive approach introduced Step 1.

Generally, the fuzzy-based techniques are useful for the situations dealing with inputs (i.e., PIs in this research), which are subjective in nature, i.e., driven from human expertise, judgment, and intuitions [37]. There are various types of uncertainties that exist, as already defined in the Introduction section, to deduce the performance, such as (i) vagueness in opinion of experts due to varying level of knowledge, particularly for qualitative PIs; and (ii) imprecise information about quantitative PIs due to limited number of measurements such as physico-chemical characteristics of leachate. Therefore, fuzzy rule-based modeling (FRBM) is used to deal with these inherent uncertainties.

Zadeh [38] introduced the fuzzy set theory to logically integrate human reasoning in decision making process. Mamdani [39] used if-then rules to develop the linguistically defined model which can deal with the subjective and uncertain knowledge and information. According to the fuzzy rules in FRBM, "If antecedent proposition, then consequent proposition." Interpretation of this expression is that if the fact (premise, hypothesis, antecedent) is known, then the conclusion (consequent) can be inferred [13]. The antecedent proposition is a fuzzy proposition of the type " $X$ is $A$," where $X$ is a linguistic variable (e.g., personnel training) and $\mathrm{A}$ is a linguistically defined constant, for example, "low," "medium," etc. A fuzzy set allows for the definition of membership values between " 0 " and " 1 ," in contrast to a classical set where the elements have to have a membership of " 0 " or " 1 ." For details, the readers are referred to Ross [40].

In present research, the UOD has been defined for PIs, performance attributes, and performance objectives using the fuzzy trapezoidal membership functions. In Figure 3, the UODs of different membership functions have be defined with the elements ( $, b, c$, and $d)$. These membership functions are attached in Appendix A for all the PIs. The fuzzy operator "AND" is used as all the PIs, PAs, and POs are independent and not mutually exclusive. For instance, the desired rule for the sub-component of "wellbeing and workplace performance" $\left(X_{2,3}\right)$ can be written as: "IF working accidents $\left(X_{2,3,1}\right)$ are 
low AND number of sick days taken per field employee $\left(X_{2,3,2}\right)$ are low AND personnel training hours $\left(\mathrm{X}_{2,3,3}\right)$ are high THEN the wellbeing and workplace performance $\left(\mathrm{X}_{2,3}\right)$ is high."

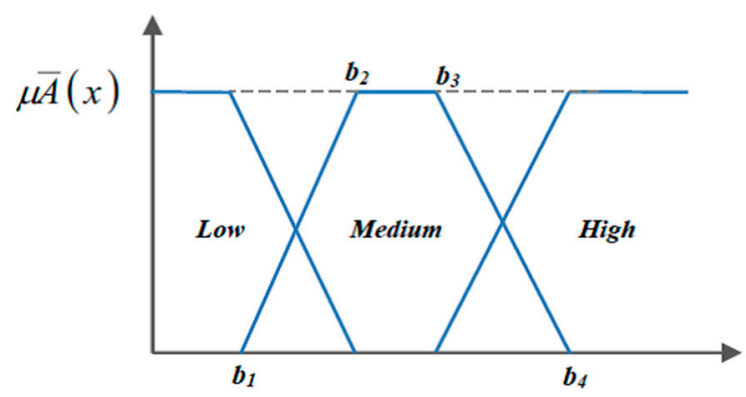

Figure 3. Trapezoidal membership function; $b_{1}, b_{2}, b_{3}$, and $b_{4}$ define the range of "medium," i.e., a fuzzy number.

In the development of PAM-SWM, a total of 495 rules were established; keeping in view the space limitations, an example of the rules for $\mathrm{X}_{2,3}$ is presented in Appendix B. Based on the structure of PAM-SWM, 18 sub models were developed for sub-components in the middle of hierarchy. Finally, all these sub-models were integrated using Simulink in MATLAB R213b (developed by MathWorks, United Sates) for inferencing the performance of seven top level key components.

\section{Step 5: Performance management of MSWM systems}

Results of PAM-SWM provide the holistic view of compliance of performance objectives to the top management of the municipality. In case of "low" and "medium" performance levels, top management can consult with the relevant operational management (e.g., landfill manager, transportation manager, etc.) for major revisions or minor improvements respectively (also see Figure 1) at the lower levels of hierarchy, i.e., PAs and subsequently the respective lacking PIs. Possibly, "low" performance at sub-component level is a result of more than one lacking PI while "medium" performance might be a reflection of a single decision variable which needs to be improved. In the case of "high" performance, the key component or the sub-components needs to be maintained. A "high" performing component, sub-component, or indicators may also require further improvements if the benchmarking process also incorporates the concept of continuous performance improvement (CPI). Discussions on integrating the CPI with the performance management of SWMs is presented at the end of Section 4.

\subsection{Study Area}

Qassim province is located in the central part of KSA. Due to extensive agricultural activities, the region holds its unique importance in the country. The study area consisting of two main cities in Qassim region is illustrated in Figure 4. Municipalities of both the cities are also located in the figure. City A is the capital and City B, located in the south of City A, is the second largest city of Qassim province. Due to industrialization and relatively moderate climatic conditions, both the cities have been experiencing an increase in population and industrialization during the recent past. Reported populations of City A and City B were around 700,000 and 185,000 (as of 2014), respectively, and is likely to increase at a higher rate in future [41]. The reported municipal solid waste generation rate is 1.2 to $1.3 \mathrm{~kg} /$ person-day for City A and 1.1 to $1.2 \mathrm{~kg} /$ person-day for City B service areas [42]. In both the cities, the primary focus of the MSWM systems is on the collection of municipal solid waste with limited source separation. Municipality of City A is encouraging citizens toward source separation by providing green color containers for recyclables; however, the initiative is at early stage. It can be seen in Figure 4 that landfill sites in both the cities are located outside the cities' boundaries to avoid nuisance of objectionable gasses. Although, City A has a functional planned industrial area, primary land uses of both the cities are residential, commercial, and public. 


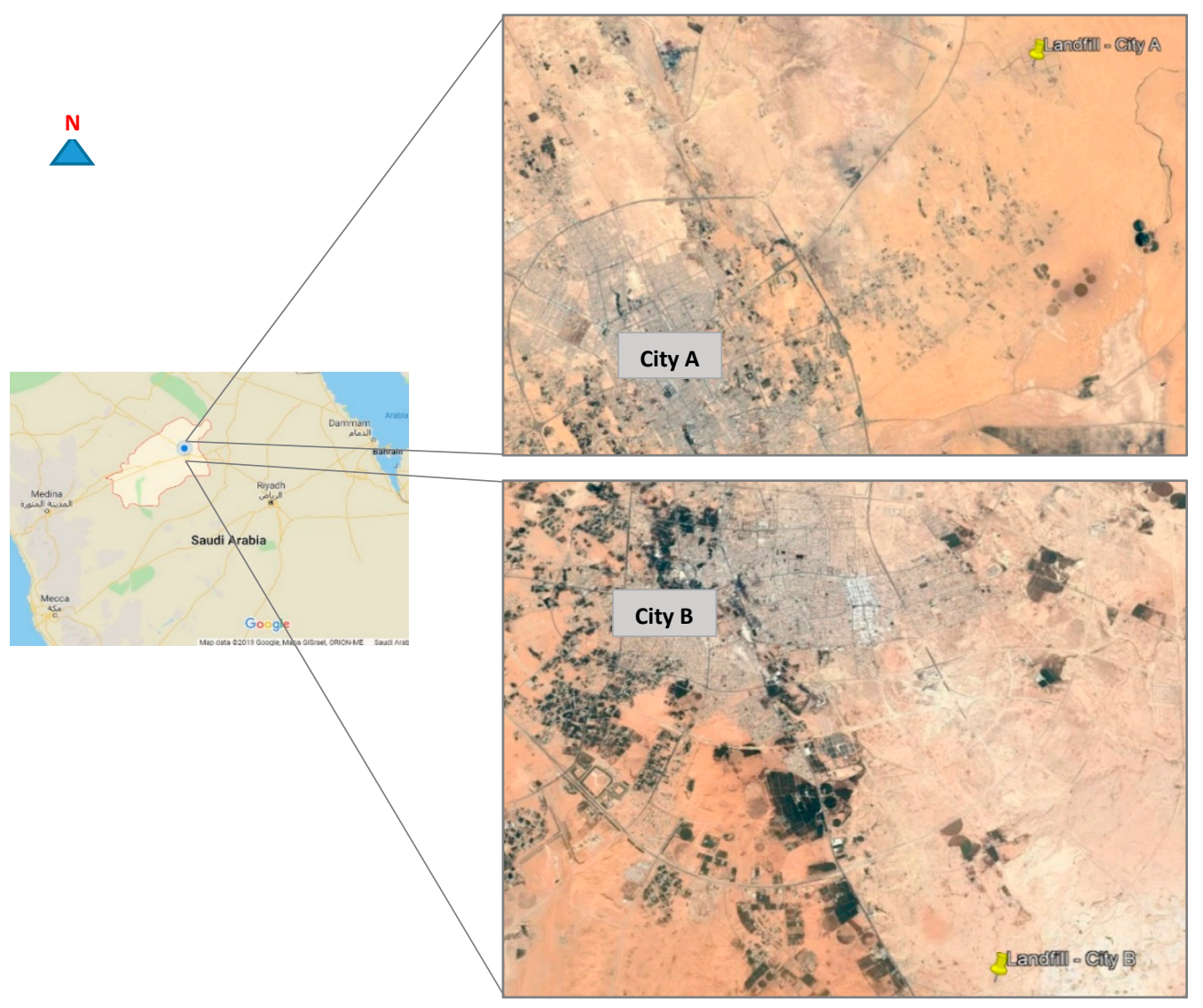

Figure 4. Study area showing locations of landfill sites in City A and City B.

Presently, the government of Kingdom of Saudi Arabia (KSA) is facing challenges of managing large volumes of solid waste due to rapid urbanization, industrialization, and high population growth rate. With a present population of around 30.8 million, more than $15.3 \mathrm{Mt}$ of solid waste is being generated annually in the country [43]. Recently, the National Transformation Program (NTP) for the year 2020 aims to: (i) improve the percentage of treated waste to at least $40 \%$ of the total waste produced, and (ii) establish an organizational framework for integrated waste management in the country by the end of year 2020. These objectives are going to be implemented through stringent controls on financial spending, focusing on high impact projects, aligning strategic priorities to the budget, rigorous auditing, and tough accountability mechanisms. It is expected that proper MSWM facilities would contribute to economy by providing job opportunities and improving waste recycling activities [42,44]. Presently, no comprehensive performance assessment mechanism exists in any of the facilities which can benchmark their existing performance, identify the lacking performance components and sub-components, and identify the possible improvements (e.g., energy recovery potential, maximize reuse, etc.) in future for CPI.

\section{Results}

The estimated daily per capita waste generation rate in KSA is 1.5 to $1.8 \mathrm{~kg} /$ capita-day [43], which is higher than the current global average of $0.74 \mathrm{~kg} /$ capita-day [1]. Municipalities of City A and City B, named as Municipality A and Municipality B, are presently covering service areas of $1400 \mathrm{~km}^{2}$ and $1200 \mathrm{~km}^{2}$, respectively. The conceivable reasons for this minor difference are: (i) much lower population density in Municipality B due to fewer industrial activities, and (ii) that the municipality covers some smaller towns located in the proximity up to $25 \mathrm{~km}$ from the main city center. The land uses in the service areas of both the municipalities are diverse, i.e., residential, agricultural, commercial, 
public, and industrial. The ground elevation of the cities above mean sea level is around $650 \mathrm{~m}$ and the terrain ranges from flat to rolling.

The performance assessment results, for the assessment period between 1 July 2016, to 30 June 2017, obtained by the PAM-SWM for both the municipalities, are illustrated with the help of web diagrams in Figure 5. It can be seen in the figure that for the key component of PSP $\left(\mathrm{X}_{1}\right)$, the performance of Municipality A (Figure 5a) was "medium" while the Municipality B lay in the "low" performance zone. For the component of PAW $\left(\mathrm{X}_{2}\right)$, both the municipalities showed "low" performance. In case of ENE $\left(X_{3}\right), \operatorname{PAE}\left(X_{4}\right)$, and SSC $\left(X_{6}\right)$, both the municipalities lay in the "medium" performance zone. Likewise, both showed "low' performance for the key component of OPR $\left(X_{5}\right)$. However, in case of EFV $\left(\mathrm{X}_{7}\right)$ component, the Municipality B outperformed the Municipality A by showing "high" performance for this key component. The municipalities are supposed to maintain their key components only when their performances lie in the light grey region in Figure 5. This color represents that all the sub-components and the PIs have met or topped the established benchmarks with "high" performance.

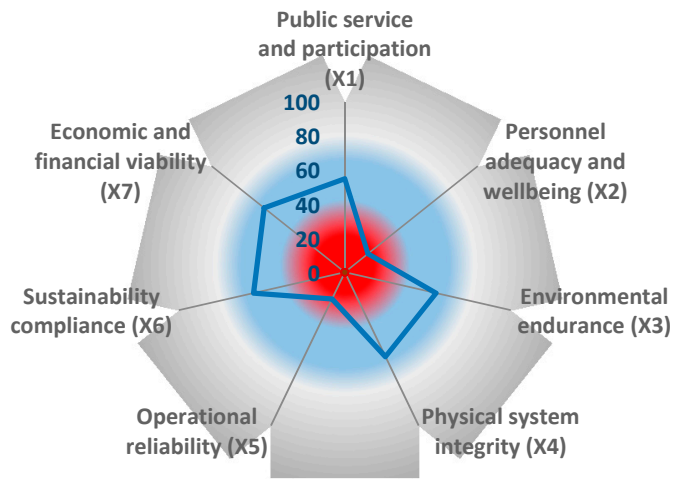

(a)

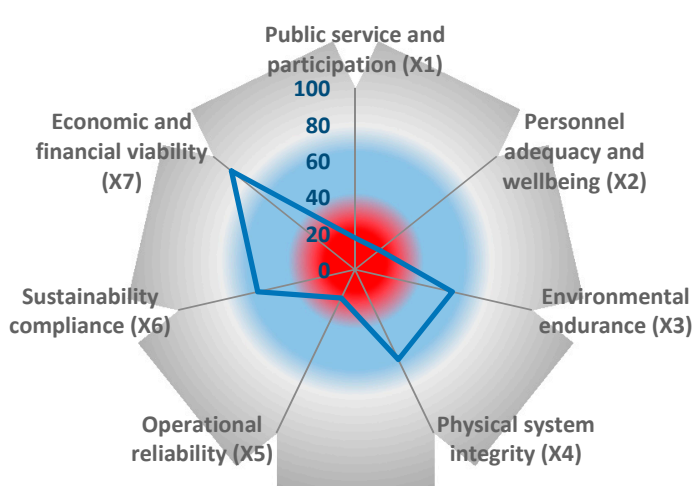

(b)

Figure 5. Performance assessment results of all the functional components of participating MSWM municipalities: (a) Municipality A, and (b) Municipality B.

The results shown in Figure 5 certainly demand to home in the performance of sub-components and the PIs for performance improvement. Accordingly, the performances of different subcomponents (Level 1) under each key component-except for $X_{6}$ and $X_{7}$, which contain no sub-component-are illustrated in Figure 6. It can be observed that the main cause of "low" performance of Municipality B was the lower "level of public participation" $\left(\mathrm{X}_{12}\right)$ in their service area. According to the manager of the participating municipality, "community's involvement in improving existing practices" $\left(X_{1,2,0,1}\right)$ and "public awareness about importance of $\mathrm{SWM}$ " $\left(\mathrm{X}_{1,2,0,3}\right)$ were essentially negligible. However, both the municipalities either need to revise or improve most of the sub-components under the component of PSP $\left(X_{1}\right)$.

In case of sub-components of PAW $\left(X_{2}\right)$, the "personnel adequacy" $\left(X_{2,1}\right)$ was found to be "medium" in the Municipality B. While for the Municipality A all the other sub-components lie in the "low" performance zone. Detailed performance scores of all the PIs are presented in Figure 7. "Personnel training" $\left(X_{2,2,0,3}\right)$ is an important component that both the municipalities need to seriously work on to meet the objectives of 2030 vision of KSA [8]. Providentially, a fewer number of sick days were noticed in the Municipality A. Both the municipalities definitely need to work on their workers' health and safety regulations and practices to avoid such high number of working accidents, i.e., $\mathrm{X}_{2,2,0,1}$. It should be noted that most of the accidents were of a trivial (e.g., slight bruising, self-help recovery, etc.) or minor (e.g., small cut, basic first aid needed, etc.) severity levels and well-mitigated at the time of occurrence; additional pro-active and careful safety measures can further reduce the frequency of such events. 


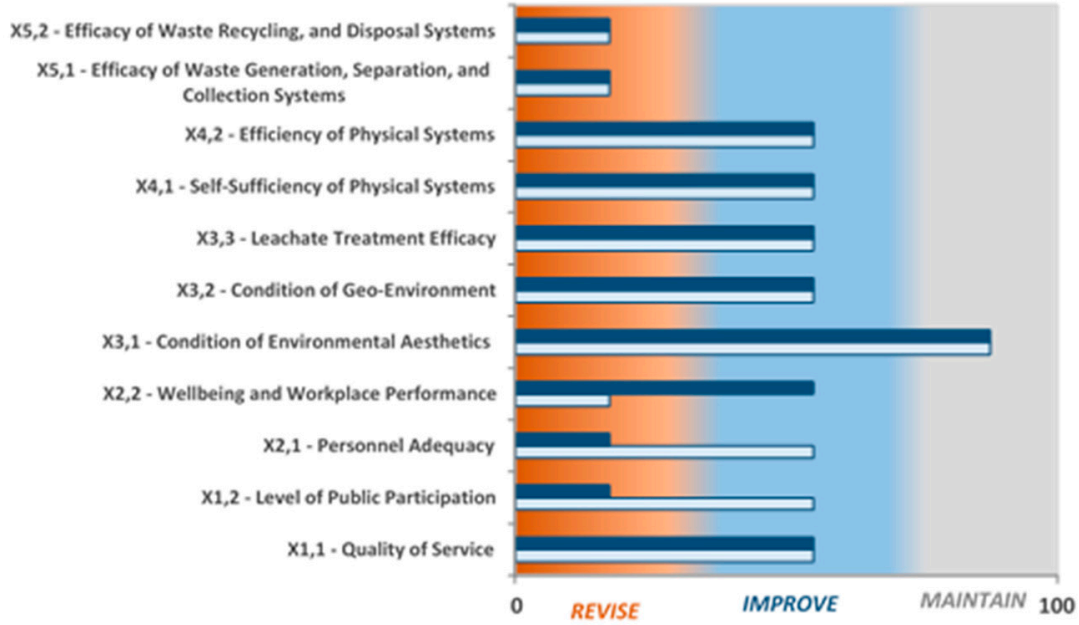

Figure 6. PAM-SWM results for all the sub-components (Level 1). Light color bars represent the performance of municipality of City A and dark color bars correspond to City B.

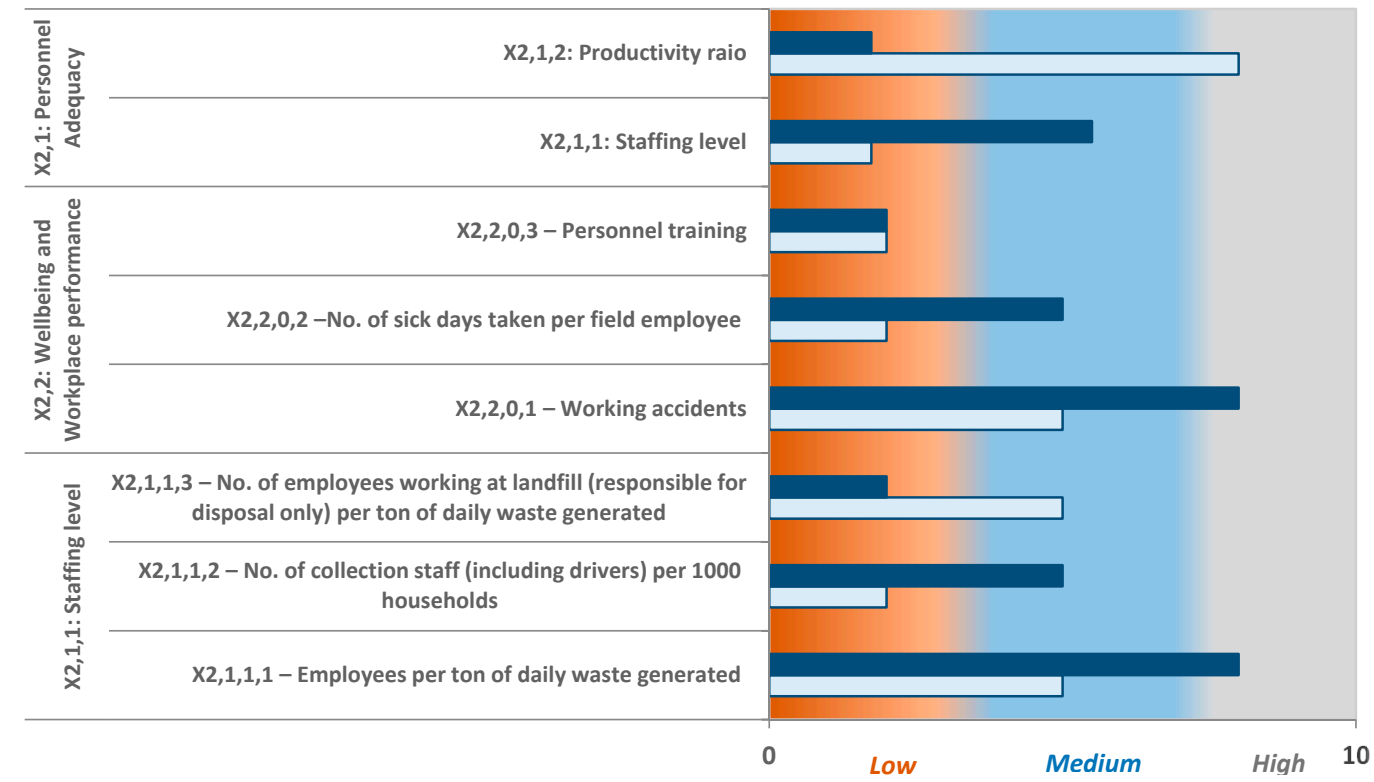

Figure 7. Example of "personnel adequacy and wellbeing" - results for generation 3 (sub-component level 2) and generation 4 (performance indicators). Light color bars represent the performance of municipality of City A and dark color bars correspond to City B.

Both the municipalities performed alike under all the sub-components of $\operatorname{ENE}\left(\mathrm{X}_{3}\right)$ component due to identical composition of waste, source separation practices, controls of visual and odor impacts, and level of leachate treatment. Existing odor control measures and bounded landfill operation resulted in "high" "condition of environmental aesthetics" $\left(\mathrm{X}_{3}, 1\right)$. The "medium" "condition of geo-environment" $\left(X_{3,2}\right)$ shows that the leachate being generated form the landfill is of a moderate strength. Presently, no appropriate leachate treatment facility exists (i.e., $X_{3,3}$ ) in any of the municipalities. As per the current leachate treatment practice, the collected leachate from the leachate collection system is sprayed on a media, consisting of mud and rocks, located within the boundaries of landfill site. The dry solids after the natural evaporation process are being incinerated.

Being the largest of two, City A has an operational material recovery facility (MRF), i.e., $\mathrm{X}_{4,1,0,1}$. In the absence of the MRF, the Municipality B is facing difficulties for extracting reusable and recyclables, e.g., glass, rubber, paper, steel, etc. In addition to low recycling efficiency (i.e., $X_{4,1,0,2}$ ), the manual separation may increase the risk of worker's health and safety at the sites. It was also found 
through personal communication that the MRF in the Municipality A was facing a few issues that need to be resolved in future, e.g., lack of technical personnel, some materials like metal and glass are not being separated for reuse, etc. Both the municipalities showed "high" equipment cleaning efficiency $\left(X_{4,2,0,1}\right)$. However, percentage of inefficient collection vehicles (i.e., $\left.X_{4,2,0,2}\right)$ was found to be high in the Municipality A.

Sub-components of both the municipalities under the component of "operational reliability" $\left(\mathrm{X}_{5}\right)$ showed "low" performance. The primary reasons of such performance of the sub-component of "efficacy of waste generation, separation, and collection systems" $\left(\mathrm{X}_{5,1}\right)$ are "improper waste storage at landfill site" $\left(X_{5,1,2,1}\right)$, low "waste separation rate of recycling" $\left(X_{5,1,2,2}\right)$, large "distance between the collection bins for recycling and the houses" $\left(\mathrm{X}_{5,1,2,3}\right)$, and low "level of collection of recyclables from the containers" $\left(\mathrm{X}_{5,1,3,2}\right)$. Few households keep the recyclables in separate plastic bags and then place them outside the property next to the collection bins. This practice should be enhanced by providing a conventional two-bin system. Currently, some medium-sized containers have been placed outside the large commercial centers located in the municipalities' service areas. Large amounts of construction and demolition waste per capita (i.e., $X_{5,1,1,1}$ ) collected at the landfill site in the Municipality B shows massive development activities in the city. However, this topic has to be dealt with in detail in a separate study. The purpose of including this PI in present research is the absence of an appropriate mechanism for C\&D waste management. At the moment, the municipalities manually sort the salvageable recyclable material from the collected C\&D waste at the landfill site and dispose the remaining into the landfill.

Both the municipalities performed "medium" for key component of "physical systems integrity" $\left(X_{6}\right)$ (refer to Figure 6). Presently, the municipalities are following international standards for ensuring workers health and safety and control measures to protect natural environment to a certain degree. Operations managers are depending on corrective maintenance strategies with reasonable effectiveness. However, the municipalities need to implement asset management strategies and sustainable practices based on detailed LCC and LCA studies which have yet to be performed.

The key component "economic and financial viability" $\left(\mathrm{X}_{7}\right)$ of the Municipality B lies in "high" performance zone. The reasons for such performance is low "disposal cost per metric ton of municipal waste" $\left(\mathrm{X}_{7,0,2}\right)$, primarily due to low cost manual operations in comparison to MRF at the Municipality A.

\section{Discussion}

The results of PAM-SWM holds dual application for performance management of MSWM systems. The first application is inter-municipality performance benchmarking where the calculated PIs can be compared amongst different participating municipalities at regional or national scale. Performance of overall key components can also be shared for cross-municipality comparison having a consensus on the concept, used in FRBM, that all the PIs have equal importance. In the second application, the municipality managers can correlate the hierarchical arrangement shown in Figure 2 to their organizational structure for intra-municipality performance management.

Practicality of PAM-SWM at different organizational levels of MSWM systems is presented in Table 2. It can be observed from the table that top/senior management is interested in the compliance of performance objective at key component level. In the case of "medium" or "low" performance results, they can direct the operational managers to hone in the attributes' performance at the sub-component levels and ultimately identify the lacking PIs at the bottom of hierarchy (also see Figure 1). For example, service manager of Municipality A needs to improve the "quality of service" $\left(\mathrm{X}_{1,1}\right)$ and "level of public participation" $\left(\mathrm{X}_{1,2}\right)$, also see Figure 6. Similarly, the health and safety manager of Municipality B was able to minimize the "number of working accidents" $\left(\mathrm{X}_{2,2,0,1}\right)$ in the given assessment period (refer to Figure 7), but needed to increase number of training hours $\left(X_{2,2,0,3}\right)$ to improve the sub-component of "wellbeing and workplace performance" $\left(\mathrm{X}_{2,2}\right)$. While the manager working at the same position in Municipality A needs to put more focused efforts to reduce $X_{2,2,0,1}$ as well as "number of sick leaves" $\left(X_{2,2,0,2}\right)$ to significantly improve (revise for major revisions) $X_{2,2}$. Major revisions could be required 
in case of "low" performance while minor improvements can fix the lacking performance in case of "medium" performance. High performing key components, performance attributes, and PIs need to be maintained. Similarly, other managers can plan improvement actions based on the performance of their corresponding sub-component.

For continuous performance improvement (CPI), in addition to appraising the current success, the municipality can further enrich their performance by selecting more resilient technologies to meet long-term sustainability objectives. The basic principle of CPI, shown in Figure 8 , revolves around continuous advancements that can be the result of incremental progression or radical changes brought forth by innovation and/or technology [45]. Present research advocates towards progression of PAM-SWM integrated with CPI approach.

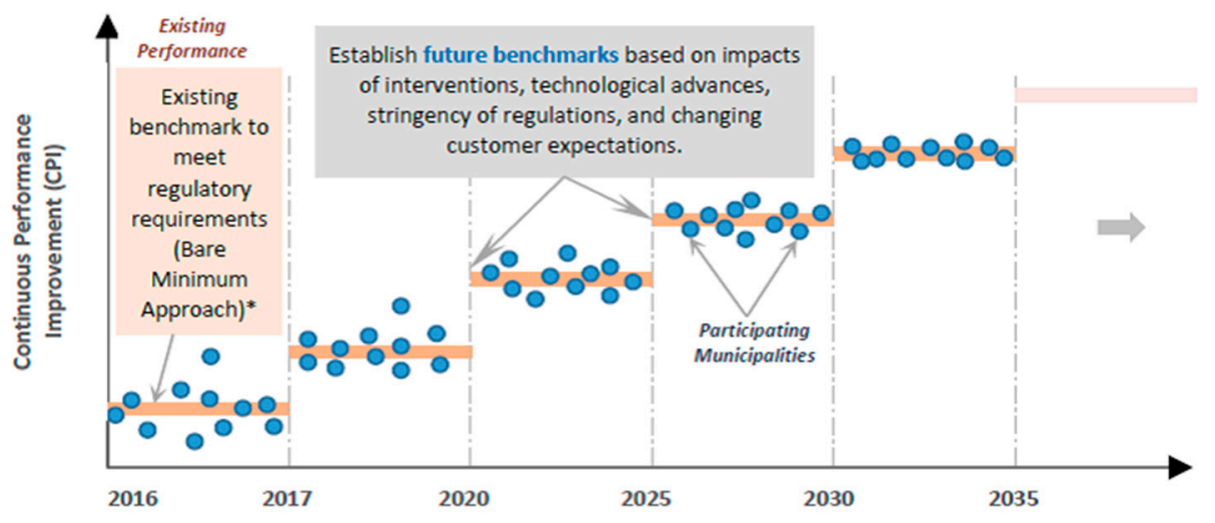

* In the absence of regulatory guidelines or benchmarks, average performance can be used to establish the present benchmark

Figure 8. Continuous performance improvement concept for MSWM Systems (modified after Bereskie et al. [45]).

The model results presented in Figures 6 and 7 (for $X_{2}$ only) should also be used for the CPI process illustrated in Figure 8 for SWMs. Future benchmarks can be established based on: (i) the findings of inter-municipality benchmarking process, where all the PIs calculated by different municipalities were compared with the existing benchmark; (ii) changing regulations (e.g., for recycling or reuse practices, environmental standards, etc.); and (iii) expected technological advances. To implement CPI for intra-municipality performance management, benchmarks can be established for performance attributes as well. Introduction of CPI in the benchmarking process will motivate the low performing municipalities to significantly improve their performance. Furthermore, and "medium" and "high" performing municipalities will strive the meet the future benchmarks. Without CPI, the "high" performing municipalities will lose their interest for further improvements and will rely on existing performance which can be declined due to unforeseen and uncontrollable factors. Instead of being ambitious towards CPI, this phenomenon can bring a "high" performing municipality to a lower performance zone, i.e., "medium," or even "low," at least in few attributes. 
Table 2. Practicality of PAM-SWM at different organizational levels of MSWM systems.

\begin{tabular}{|c|c|c|c|c|c|c|c|c|c|c|c|}
\hline $\begin{array}{l}\text { Generation } 1 \text {-Component } \\
\text { (Performance Objectives) }\end{array}$ & $\begin{array}{l}\text { Generation 2-Sub-Components } \\
\text { (Level 1) } \\
\text { (Performance Measures) }\end{array}$ & $\begin{array}{l}\text { Top/Senior } \\
\text { Managers }\end{array}$ & $\begin{array}{l}\text { Services } \\
\text { Manager }\end{array}$ & $\begin{array}{c}\text { Waste } \\
\text { Collection } \\
\text { Manager }\end{array}$ & $\begin{array}{l}\text { Operations } \\
\text { Manager }\end{array}$ & $\begin{array}{c}\text { Asset } \\
\text { Manager }\end{array}$ & $\begin{array}{l}\text { Transport } \\
\text { Manager }\end{array}$ & $\begin{array}{l}\text { Human } \\
\text { Resource } \\
\text { Manager }\end{array}$ & $\begin{array}{l}\text { Health } \\
\text { and Safety } \\
\text { Manager }\end{array}$ & $\begin{array}{l}\text { Environment and } \\
\text { Sustainability } \\
\text { Manager }\end{array}$ & $\begin{array}{l}\text { Finance } \\
\text { Manager }\end{array}$ \\
\hline \multirow[t]{3}{*}{$\begin{array}{l}\mathbf{X}_{1} \text {-Public Service and } \\
\text { Participation (PSP) }\end{array}$} & - & $\sqrt{ }$ & & & & & & & & & \\
\hline & $\mathrm{X}_{1,1}$-Quality of Service & & $\sqrt{ }$ & $\sqrt{ }$ & & & $\sqrt{ }$ & & & & \\
\hline & $\mathbf{X}_{1,2}$-Level of Public Participation & & $\sqrt{ }$ & & & & $\sqrt{ }$ & & & $\sqrt{ }$ & \\
\hline $\begin{array}{l}X_{2} \text {-Personnel adequacy and } \\
\text { wellbeing (PAW) }\end{array}$ & - & $\sqrt{ }$ & & & & & & & & & \\
\hline- & $\mathrm{X}_{2,1}$-Personnel Adequacy & & & & $\sqrt{ }$ & & & $\sqrt{ }$ & & & $\sqrt{ }$ \\
\hline- & $\begin{array}{l}\mathbf{X}_{2,2} \text {-Wellbeing and workplace } \\
\text { performance }\end{array}$ & & & & & & & $\sqrt{ }$ & $\sqrt{ }$ & & \\
\hline $\begin{array}{l}\mathrm{X}_{3} \text {-Environmental Endurance } \\
\text { (ENE) }\end{array}$ & - & $\sqrt{ }$ & & & & & & & & & \\
\hline- & $\begin{array}{l}\mathbf{X}_{3,1} \text {-Condition of environmental } \\
\text { aesthetics }\end{array}$ & & & & $\sqrt{ }$ & & & & $\sqrt{ }$ & $\sqrt{ }$ & \\
\hline- & $\begin{array}{l}\mathbf{X}_{3,2} \text {-Condition of } \\
\text { geo-environment }\end{array}$ & & & & $\sqrt{ }$ & & & & $\sqrt{ }$ & $\sqrt{ }$ & \\
\hline- & $\mathrm{X}_{3,3}$-Leachate treatment efficacy & & & & $\sqrt{ }$ & & & & $\sqrt{ }$ & $\sqrt{ }$ & \\
\hline $\mathbf{X}_{4}$-Physical Assets Efficacy (PAE) & - & $\sqrt{ }$ & & & & & & & & & \\
\hline- & $\begin{array}{l}\mathbf{X}_{4,1} \text {-Self-sufficiency of Physical } \\
\text { Systems }\end{array}$ & & & $\sqrt{ }$ & $\sqrt{ }$ & $\sqrt{ }$ & & & & & $\sqrt{ }$ \\
\hline- & $\begin{array}{l}\mathbf{X}_{4,2} \text {-Efficiency of physical } \\
\text { systems }\end{array}$ & & & $\sqrt{ }$ & $\sqrt{ }$ & $\sqrt{ }$ & & & & & \\
\hline $\mathrm{X}_{5}$-Operational Reliability (OPR) & - & $\sqrt{ }$ & & & & & & & & & \\
\hline- & $\begin{array}{l}\mathrm{X}_{5,1} \text {-Efficacy of waste generation, } \\
\text { separation, and collection } \\
\text { systems }\end{array}$ & & & $\sqrt{ }$ & $\sqrt{ }$ & & $\sqrt{ }$ & & & $\sqrt{ }$ & \\
\hline- & $\begin{array}{l}\mathbf{X}_{5,2} \text {-Efficacy of waste recycling, } \\
\text { and disposal systems }\end{array}$ & & & & $\sqrt{ }$ & & & & & $\sqrt{ }$ & \\
\hline $\begin{array}{l}\mathrm{X}_{6} \text {-Sustainability Compliance } \\
\text { (SSC) }\end{array}$ & - & $\sqrt{ }$ & & & & & & & & $\sqrt{ }$ & \\
\hline $\begin{array}{l}X_{7} \text {-Economic and Financial } \\
\text { Viability (EFV) }\end{array}$ & - & $\sqrt{ }$ & & & & & & & & & $\sqrt{ }$ \\
\hline
\end{tabular}


PAM-SWM will be a useful tool for solid waste managers to evaluate (calculation of PIs), assess (comparison with benchmarks), and improve their SWMs in KSA, Gulf, and similar regions around the globe where modern SWM has more recently been adopted.

Although, an important outcome of the benchmarking process is the motivation to performance improvement, disproportionate comparison (i.e., comparing all size classes against the same benchmarks) may lead to discouraging outcomes in underperforming municipalities, which generally are small-to-medium-sized. For such systems with limited resources, the collection of baseline data and developing proper inventories required for benchmarking process itself is an intimidating task. Benchmarking without considering the proportionality between the participating municipalities may lead to misleading outcomes. Generally, large systems perform better as compared to the smaller systems due to their higher economies-of-scale [46]. As a result, participation of smaller municipalities in the regional benchmarking process is generally negligible [10].

Despite several applications, PAM-SWM holds some limitations. Karthikeyan et al. [47] identified the root causes of underperforming hazardous waste management systems in developing countries, such as insufficient treatment process, noncompliance of standards, training inadequacies, and a non-supportive governance system. PIs to address these areas were not included in PAM-SWM; their inclusion in future studies is recommended. A closed loop system (i.e., cradle-to-cradle), based on a circular economy, has been well-recognized for integrated waste management to achieve long-term sustainability objectives [48]. In future, PIs related to sustainability of integrated waste management, such as material stewardship, eco-efficiency, reuse of biodegradables, etc., can be included in PAM-SWM under relevant components and sub-components.

\section{Conclusions}

The performance assessment model for municipal solid waste management (PAM-SWM) can be used for both the inter-municipality and intra-municipality performance benchmarking. The hierarchical model framework based on deductive reasoning facilitates the managers of SWM systems responsible for various process operations. Model outcomes provide the rationale for minor or major improvements required for long-term sustainability of MSWM systems. Performance objectives showing the performance of the key component are useful for top management. Operations managers can monitor sub-components using performance attributes at level 1 and 2 of the model's hierarchy.

Model application on two municipalities operating in Qassim region shows the practicality of PAM-SWM in KSA. Model results revealed that the participating municipalities need significant reforms for the sustainability of their MSWM systems. In particular, they need major upgrades on "workers' health and safety" and "personnel training" for improving the key component of "personnel adequacy and wellbeing." Municipalities also need immediate and significant actions to improve the reliability of their operations.

The performance criteria consisting of performance objectives, attributes, and indicators for the development of PAM-SWM have been defined by the experts from academia and field (municipality mangers) and literature. Although, the participating municipalities in Qassim region (KSA) were fully involved in the selection of indicators, the model can be further validated by appreciating the opinion of additional stakeholders from other academic institutions, municipalities operating outside Qassim region, and participants from relevant agencies at large.

Lacking data and inadequate inventory management systems are common problems, particularly in small-sized and medium-sized municipalities. Knowledge of experts was used to derive the qualitative PIs. Such assessment processes contain inherent uncertainties. Fuzzy rule-based modeling technique used for performance inferencing in PAM-SWM can effectively account for these uncertainties.

The hierarchical based framework of PAMSWM can easily accommodate additional performance criteria, at any level of the hierarchy, due to expansion of physical infrastructure, changes in regulations as a result of well-established and regular benchmarking process at national and regional 
levels, and considerations to hazardous waste management, circular economy, and impacts of technological progresses.

In the absence of information required to establish benchmarks, the universe of discourse was formed for evaluating the performance criteria based on literature, and expert system. It is highly recommended to fine-tune the developed universe of discourse based on actual benchmarking process and implementation of continuous performance improvement process for MSWM systems in Saudi Arabia or elsewhere.

Author Contributions: Conceptualization, H.A.A., H.H., S.S.A., M.S. and R.S.; Data curation, H.A.A. and H.H.; Formal analysis, H.A.A. and H.H.; Methodology, H.A.A., H.H., S.S.A., M.A. and M.S.; Project administration, H.H.; Resources, H.A.A.; Software, H.A.A. and H.H.; Validation, H.A.A. and H.H.; Visualization, M.A. and R.S.; Writing-original draft, H.A.A. and H.H.; Writing-review \& editing, H.H., S.S.A., M.A., M.S. and R.S.

Funding: This research received no external funding.

Acknowledgments: The data provided by the municipalities in Qassim Region is highly appreciated. Support of Civil Engineering Department, College of Engineering, Qassim University is acknowledged.

Conflicts of Interest: The authors declare no conflict of interest.

Appendix A

Table A1. Universe of discourse (UOD) of performance indicators.

\begin{tabular}{|c|c|c|c|c|c|}
\hline \multirow{2}{*}{ NO. } & \multirow{2}{*}{ Performance Indicator (PI) } & \multirow{2}{*}{ Units } & \multicolumn{3}{|c|}{ Universe of Discourse (UOD) } \\
\hline & & & Low & Medium & High \\
\hline PU & Public Service and Participation (PSP) & - & - & - & - \\
\hline PU1 & Solid waste production per capita & $\mathrm{kg} / \mathrm{cap} /$ day & $1-1.3$ & $1.2-1.6$ & $1.5-2$ \\
\hline PU2 & Coverage of the collection service & $\%$ & $<75-85$ & $80-95$ & $90-100>$ \\
\hline PU3 & $\begin{array}{l}\text { Persons not satisfied with the waste } \\
\text { management services }\end{array}$ & $\%$ & $<10-25$ & $20-40$ & $30-50>$ \\
\hline PU4 & $\begin{array}{l}\text { community's involvement in improving } \\
\text { existing practices }\end{array}$ & Qualitative & $0-4$ & $2.5-7.5$ & $6-10$ \\
\hline PU5 & $\begin{array}{l}\text { Public acceptance of waste management } \\
\text { plans and actions }\end{array}$ & Qualitative & $0-4$ & $2.5-7.5$ & $6-10$ \\
\hline PU6 & $\begin{array}{l}\text { Community awareness about importance of } \\
\text { SWM }\end{array}$ & Qualitative & $0-4$ & $2.5-7.5$ & $6-10$ \\
\hline PE & Personnel Productivity & - & - & - & - \\
\hline PE1 & Employees per ton of daily waste generated & No. of employees/ton & $0-3$ & $<2-5>$ & $4-6>$ \\
\hline PE2 & $\begin{array}{l}\text { No. of collection staff (including drivers) per } \\
1000 \text { households }\end{array}$ & $\begin{array}{c}\text { No. of collection } \\
\text { staff/1000 household } \\
\text { served }\end{array}$ & $<10-25$ & $<20-40>$ & $35-60>$ \\
\hline PE3 & $\begin{array}{l}\text { No. of employees working at landfill } \\
\text { (responsible for disposal only) per ton of } \\
\text { daily waste generated }\end{array}$ & $\begin{array}{l}\text { No. of employees in } \\
\text { landfill/ton }\end{array}$ & $<0.1-0.3$ & $<0.25-0.5>$ & $0.45-0.7>$ \\
\hline PE4 & Working accidents & $\begin{array}{c}\text { (No./100 } \\
\text { employee/year) }\end{array}$ & $0-3$ & $<2-6>$ & $5-10>$ \\
\hline PE5 & No. of sick days taken per field employee & $\begin{array}{l}\text { No. of sick days/field } \\
\text { employee }\end{array}$ & $0-5$ & $3-10$ & $8-20>$ \\
\hline PE6 & Personnel Training & (Hours/employee/year) & $0-10$ & $8-25$ & $20-50>$ \\
\hline EN & Environmental Stability & - & - & - & - \\
\hline EN1 & Visual impact & Qualitative & $0-4$ & $2.5-7.5$ & $6-10$ \\
\hline EN2 & Odor impact & Qualitative & $0-5$ & $2.5-7.5$ & $6-10$ \\
\hline EN3 & Temperature of leachate & $\left({ }^{\circ} \mathrm{C}\right)$ & $0-25$ & $<20-50>$ & $45>$ \\
\hline EN4 & (TDS) in leachate & $\mathrm{mg} / \mathrm{L}$ & $0-20000$ & $<15000-40000>$ & $35000-50000>$ \\
\hline EN5 & Total suspended solid (TSS) & $\mathrm{mg} / \mathrm{L}$ & $200-500$ & $400-1000$ & $800-2000$ \\
\hline EN6 & BOD in leachate & $\mathrm{mg} / \mathrm{L}$ & $<2000-6000$ & $<5000-12000>$ & $11000-30000>$ \\
\hline EN7 & COD in leachate & $\mathrm{mg} / \mathrm{L}$ & $<3000-10000$ & $<9000-20000>$ & $19000-60000>$ \\
\hline EN8 & BOD/COD Ratio & Ratio & $0.3-0.4$ & $0.35-0.5$ & $0.45-0.6$ \\
\hline EN9 & Nitrates (NO3) & $\mathrm{mg} / \mathrm{L}$ & $<5-20$ & $15-40$ & $30-60$ \\
\hline
\end{tabular}


Table A1. Cont.

\begin{tabular}{|c|c|c|c|c|c|}
\hline \multirow{2}{*}{ NO. } & \multirow{2}{*}{ Performance Indicator (PI) } & \multirow{2}{*}{ Units } & \multicolumn{3}{|c|}{ Universe of Discourse (UOD) } \\
\hline & & & Low & Medium & High \\
\hline EN10 & Phosphorus concentration in leachate & $\mathrm{mg} / \mathrm{L}$ & $1-25$ & $20-50$ & $40-100$ \\
\hline EN11 & ammonia concentration in leachate & $\mathrm{mg} / \mathrm{L}$ & $<10-150$ & $100-500$ & $400-800>$ \\
\hline PH & Physical Systems Integrity & - & - & - & - \\
\hline PH1 & Presence of material recovery facility (MRF) & YES/NO & $0-2$ & - & $8-10$ \\
\hline PH2 & Lack of appropriate waste recycling facilities & Qualitative & $0-4$ & $2.5-7.5$ & $6-10$ \\
\hline PH3 & Equipment cleaning frequency & NO./year & $0-150$ & $100-300$ & $250-365$ \\
\hline PH4 & Inefficient waste collection vehicles & $\begin{array}{l}\text { NO./total collection } \\
\text { vehicles }\end{array}$ & $0-0.2$ & $0.15-0.4$ & $0.3-0.6$ \\
\hline OP & Operational Efficiency & - & - & - & - \\
\hline OP1 & $\begin{array}{l}\text { Amount of construction and demolition } \\
\text { generated per year }\end{array}$ & ton/person-year & $0.01-0.1$ & $0.05-0.2$ & $0.15-0.3$ \\
\hline OP2 & $\begin{array}{l}\text { Segregation of waste collected for each } \\
\text { category }\end{array}$ & Qualitative & $0-4$ & $2.5-7.5$ & $6-10$ \\
\hline OP3 & Improper waste storage at landfill & $\%$ & $0.01-1$ & $0.7-1.5$ & $1.3-2>$ \\
\hline OP4 & Waste separation rate for recycling & ton/year & $<1-20$ & $10-50$ & $40-80>$ \\
\hline OP5 & $\begin{array}{l}\text { Average distance between collection bins for } \\
\text { recycles and the houses }\end{array}$ & $\mathrm{m}$ & $<30-50$ & $40-100$ & $80-200>$ \\
\hline OP6 & $\begin{array}{l}\text { Average distance travelled by collection } \\
\text { vehicle }\end{array}$ & km/vehicle-day & $<10-30$ & $20-40$ & $30-50$ \\
\hline OP7 & $\begin{array}{l}\text { Level of collection of recyclables from the } \\
\text { containers }\end{array}$ & Qualitative & $0-4$ & $2.5-7.5$ & $6-10$ \\
\hline OP8 & $\begin{array}{l}\% \text { of construction and demolition waste } \\
\text { recycled }\end{array}$ & $\%$ & $<10-40$ & $30-70$ & $60-80>$ \\
\hline OP9 & $\%$ of municipal solid waste recycled & $\%$ & $<10-40$ & $30-70$ & $60-80>$ \\
\hline OP10 & Total tonnage of municipal waste landfilled & $\%$ & $<20-40$ & $30-70$ & $60-100$ \\
\hline OP11 & $\begin{array}{l}\text { Amount of waste disposed to the landfill in } \\
\text { addition to municipal waste from other } \\
\text { sources (e.g., industry, agriculture, } \\
\text { construction) }\end{array}$ & $\%$ & $<20-40$ & $30-70$ & $60-100$ \\
\hline OP12 & Remaining service life & year & $20-40$ & $30-50$ & $40-60>$ \\
\hline SU & Sustainability Performance & - & - & - & - \\
\hline SU1 & $\begin{array}{l}\text { Rate of increase total amount of MSW } \\
\text { generation }\end{array}$ & $\%$ & $<2-5$ & $4-8$ & $7-10>$ \\
\hline SU2 & $\begin{array}{l}\text { Application of life cycle costing (LCC) and } \\
\text { life cycle assessment (LCA) }\end{array}$ & Qualitative & $0-4$ & $2.5-7.5$ & $6-10$ \\
\hline SU3 & Treatment facilities dynamics & Qualitative & $0-4$ & $2.5-7.5$ & $6-10$ \\
\hline EF & Economic and Financial viability & - & - & - & - \\
\hline EF1 & Collection cost/ton of waste generated & SR/ton & $100-400$ & $300-600$ & $500-1000>$ \\
\hline EF2 & $\begin{array}{l}\text { Cost of municipal wastes disposal per metric } \\
\text { ton }\end{array}$ & $\mathrm{SR} /$ ton & $15-30$ & $25-50$ & $40-100>$ \\
\hline EF3 & Recycling cost/ton of waste generated & $\mathrm{SR} /$ ton & $15-30$ & $25-50$ & $40-100>$ \\
\hline
\end{tabular}

\section{Appendix B}

Table A2. Matrix defining fuzzy rules for the "wellbeing and workplace performance".

\begin{tabular}{|c|c|c|c|c|}
\hline Rule No & $\begin{array}{l}\text { Working } \\
\text { Accidents * } \\
\left(\mathrm{X}_{2,3,0,1}\right)\end{array}$ & $\begin{array}{c}\text { No. of Sick Days } \\
\text { Taken per Field } \\
\text { Employee } *\left(X_{2,3,0,2}\right)\end{array}$ & $\begin{array}{c}\text { Personnel } \\
\text { Training ** } \\
\left(X_{2,3,0,3}\right)\end{array}$ & $\begin{array}{c}\text { Wellbeing and } \\
\text { Workplace } \\
\text { Performance } * *\left(X_{2,3}\right)\end{array}$ \\
\hline 1 & Low & Low & Low & Medium \\
\hline 2 & Low & Low & Medium & Medium \\
\hline 3 & Low & Low & High & High \\
\hline 4 & Low & Medium & Low & Medium \\
\hline
\end{tabular}


Table A2. Cont.

\begin{tabular}{|c|c|c|c|c|}
\hline Rule No & $\begin{array}{c}\text { Working } \\
\text { Accidents * } \\
\left(\mathrm{X}_{2,3,0,1}\right)\end{array}$ & $\begin{array}{c}\text { No. of Sick Days } \\
\text { Taken per Field } \\
\text { Employee * }\left(X_{2,3,0,2}\right)\end{array}$ & $\begin{array}{c}\text { Personnel } \\
\text { Training ** } \\
\left(X_{2,3,0,3}\right)\end{array}$ & $\begin{array}{c}\text { Wellbeing and } \\
\text { Workplace } \\
\text { Performance } * *\left(X_{2,3}\right)\end{array}$ \\
\hline 5 & Low & Medium & Medium & Medium \\
\hline 6 & Low & Medium & High & Medium \\
\hline 7 & Low & High & Low & Low \\
\hline 8 & Low & High & Medium & Medium \\
\hline 9 & Low & High & High & Medium \\
\hline 10 & Medium & Low & Low & Medium \\
\hline 11 & Medium & Low & Medium & Medium \\
\hline 12 & Medium & Low & High & Medium \\
\hline 13 & Medium & Medium & Low & Medium \\
\hline 14 & Medium & Medium & Medium & Medium \\
\hline 15 & Medium & Medium & High & Medium \\
\hline 16 & Medium & High & Low & Low \\
\hline 17 & Medium & High & Medium & Medium \\
\hline 18 & Medium & High & High & Medium \\
\hline 19 & High & Low & Low & Low \\
\hline 20 & High & Low & Medium & Medium \\
\hline 21 & High & Low & High & Medium \\
\hline 22 & High & Medium & Low & Low \\
\hline 23 & High & Medium & Medium & Medium \\
\hline 24 & High & Medium & High & Medium \\
\hline 25 & High & High & Low & Low \\
\hline 26 & High & High & Medium & Low \\
\hline 27 & High & High & High & Low \\
\hline
\end{tabular}

\section{References}

1. World Bank. Solid Waste Management. 2018. Available online: www.worldbank.org/en/topic/ urbandevelopment/brief/solid-waste-management (accessed on 1 January 2019).

2. Sequeiros, B. Application of performance indicators in municipal waste services. Técnico Lisboa. 2012, 12, $1-10$.

3. Armijo, C.; Puma, A.; Ojeda, S. A Set of Indicators for Waste Management Programs. Available online: https: / / pdfs.semanticscholar.org/c75a/f83f3aa51a8af4e8ff9b0b4afe46ff33d034.pdf (accessed on 1 January 2019).

4. Byamba, B.; Ishikawa, M. Municipal Solid Waste Management in Ulaanbaatar Mongolia: Systems Analysis. Sustainability 2017, 9, 896. [CrossRef]

5. Rigamonti, L.; Sterpi, I.; Grosso, M. Integrated municipal waste management systems: An indicator to assess their environmental and economic sustainability. Ecol. Ind. 2016, 60, 1-7. [CrossRef]

6. Zaman, A. Identification of key assessment indicators of the zero waste management systems. Ecol. Ind. 2014, 36, 682-693. [CrossRef]

7. United Nations. Transforming Our World: The 2030 Agenda for Sustainable Development. Available online: https:/ / sustainabledevelopment.un.org/post2015/transformingourworld (accessed on 1 December 2017).

8. Kingdom of Saudi Arabia Vision 2030. Available online: http://vision2030.gov.sa/sites/default/files/ report/Saudi_Vision2030_EN_0.pdf (accessed on 1 January 2019). 
9. Haider, H.; Sadiq, R.; Tesfamariam, S. Performance indicators for small and medium sized water supply systems: A review. Environ. Rev. 2014, 22, 1-40. [CrossRef]

10. Haider, H.; Sadiq, R.; Tesfamariam, S. Inter-Utility Performance Benchmarking Model for Small-to-Medium-Sized Water Utilities: Aggregated Performance Indices. J. Water Res. Plann. Manag. 2016, 142, 04015039. [CrossRef]

11. Zotos, G.; Karagiannidis, A.; Zampetoglou, S.; Malamakis, A.; Antonopoulos, I.-S.; Kontogianni, S.; Tchobanoglous, G. Developing a holistic strategy for integrated waste management within municipal planning: Challenges, policies, solutions and perspectives for Hellenic municipalities in the zero-waste, low-cost direction. Waste Manag. 2009, 29, 1686-1692. [CrossRef] [PubMed]

12. Plant, T. Strategic planning for municipalities: Ensuring progress and relevance. Perform. Imp. 2009, 48, 26-35. [CrossRef]

13. Haider, H.; Sadiq, R.; Tesfamariam, S. Intra-utility Performance Management Model (In-UPM) for the sustainability of small to medium sized water utilities: Conceptualization to development. J. Clean. Prod. 2016, 133, 777-794. [CrossRef]

14. Coelho, H.M.G.; Lange, L.C.; Coelho, L.M.G. Proposal of an environmental performance index to assess solid waste treatment technologies. Waste Manag. 2012, 32, 1473-1481. [CrossRef] [PubMed]

15. Donevska, K.R.; Gorsevski, P.V.; Jovanovski, M.; Peševski, I. Regional nonhazardous landfill site selection by integrating fuzzy logic, AHP and geographic information systems. Environ. Ear. Sci. 2012, 67, 121-131. [CrossRef]

16. Din, S.U.; Oskui, R.P.; Dusseault, M.B. Multi-criteria evaluation technique for SFI site identification of NORMS and oil industry waste disposal-possibilities in Kuwait. J. Environ. Manag. 2009, 91, 186-194. [CrossRef] [PubMed]

17. Cherubini, F.; Bargigli, S.; Ulgiati, S. Life cycle assessment (LCA) of waste management strategies: Landfilling, sorting plant and incineration. Energy 2009, 34, 2116-2123. [CrossRef]

18. Mendes, P.; Santos, A.C.; Nunes, L.M.; Teixeira, M.R. Evaluating municipal solid waste management performance in regions with strong seasonal variability. Ecolog. Ind. 2013, 30, 170-177. [CrossRef]

19. Guerrini, A.; Carvalho, P.; Romano, G.; Marques, R.C.; Leardini, C. Assessing efficiency drivers in municipal solid waste collection services through a non-parametric method. Clean. Prod. 2017, 147, 431-441. [CrossRef]

20. Căilean, D.; Teodosiu, C. An assessment of Romanian solid waste management system based on sustainable development indicators. Sustain. Prod. Cons. 2016, 10, 45-56.

21. Anestina, A.I.; Adetola, A.; Odafe, I.B. Performance Assessment of Solid Waste Management following Private Partnership Operations in Lagos State, Nigeria. J. Wast. Manag. 2014, 868072, 1-8. [CrossRef]

22. Huang, Y.; Pan, T.; Kao, J. Performance assessment for municipal solid waste collection in Taiwan. Environ. Manag. 2011, 92, 1277-1283. [CrossRef] [PubMed]

23. Lohri, C.R.; Camenzind, E.J.; Zurbrügg, C. Financial sustainability in municipal solid waste management-Costs and revenues in Bahir Dar, Ethiopia. Waste Manag. 2014, 34, 542-552. [CrossRef] [PubMed]

24. Abbondanza, M.N.M.; Souza, R.G. Estimating the generation of household e-waste in municipalities using primary data from surveys: A case study of Sao Jose dos Campos, Brazil. Waste Manag. 2019, 85, 374-384. [CrossRef]

25. Zaman, A. Measuring waste management performance using the 'Zero Waste Index': The case of Adelaide, Australia. J. Clean. Prod. 2014, 66, 407-419. [CrossRef]

26. California Water Environment Association (CWEA). Available online: www.cwea.org/p3s/documents / multi-sectorrev.pdf (accessed on 1 March 2018).

27. McMillan, H.; Krueger, T.; Freer, J. Benchmarking observational uncertainties for hydrology: Rainfall, river discharge and water quality. Hydrol. Proc. 2012, 26, 4078-4111. [CrossRef]

28. Galar, D.; Berges, L.; Sandborn, P.; Kumar, U. The need for aggregated indicators in performance asset management. Maint. Reliab. 2014, 16, 120-127.

29. Haider, H.; Sadiq, R.; Tesfamariam, S. Risk-Based Framework for Improving Customer Satisfaction through System Reliability in Small-Sized to Medium-Sized Water Utilities. J. Manag. Eng. 2016, 32, 04016008. [CrossRef]

30. Dubanowitz, A.J. Design of a Materials Recovery Facility (MRF) For Processing the Recyclable Materials of New York City's Municipal Solid Waste. Master's Thesis, Columbia University, New York, NY, USA, 2000. 
31. Agamuthu, P. Waste Management and Recycling Performance Indicators: Priorities and Challenges, Institute of Biological Sciences, University of Malaya, Kuala Lumpur, Malaysia. Available online: www.iges.or.jp/en/ archive/wmr/pdf/activity20121213/1-4_Agamuthu.pdf (accessed on 1 January 2018).

32. Gautam, A.K.; Kumar, S. Strategic planning of recycling options by multi-objective programming in a GIS environment. Clean Technol. Environ. Pol. 2005, 7, 306-316. [CrossRef]

33. Bautista, J.; Pereira, J. Modelling the problem of locating collection areas for urban waste management. An application to the metropolitan area of Barcelona. Omega 2006, 34, 617-629. [CrossRef]

34. Pires, A.; Martinho, G.; Chang, N. Solid waste management in European countries: A review of systems analysis techniques. J. Environ. Manag. 2011, 92, 1033-1050. [CrossRef] [PubMed]

35. Abduli, M.A.; Naghib, A.; Yonesi, M.; Akbari, A. Life cycle assessment (LCA) of solid waste management strategies in Tehran: Landfill and composting plus landfill. Environ. Mon. Assess. 2011, 178, 487-498. [CrossRef] [PubMed]

36. Lundin, U. Indicators for Measuring the Sustainability of Urban Water Systems-A Life Cycle Approach. Ph.D. Thesis, Chalmers University of Technology, Goteborg, Sweden, 2003.

37. Sadiq, R.; Kleiner, Y.; Rajani, B.; Tesfamariam, S.; Haider, H. Modelling water quality failures potential in distribution systems: Q-WARP development and application. J. Water Supply Res. Technol. AQUA 2014, 63, 429-448. [CrossRef]

38. Zadeh, L.A. Fuzzy Sets as a Basis for a Theory of Possibility. Fuzzy Sets Syst. 1978, 1, 3-28. [CrossRef]

39. Mamdani, E.H. Application of fuzzy logic to approximate reasoning using linguistic systems. Fuzzy Sets Syst. 1977, 26, 1182-1191.

40. Ross, T. Fuzzy Logic with Engineering Applications; John Wiley and Sons: New York, NY, USA, 2004.

41. Population.city. Available online: population.city/saudi-arabia/buraydah/ (accessed on 2 February 2018).

42. Kuaie, M. Quantity of Waste in the Kingdom and What is Recycled in the Gulf, Al-Riyadh Daily, Al-Riyadh City. Saudi Arabia. 2014. Available online: http://www.alriyadh.com/941975 (accessed on 1 December 2017).

43. Anjum, M.; Miandad, R.; Waqas, M.; Ahmad, I.; Alafif, Z.O.A.; Aburiazaiza, A.S.; Barakst, M.A.E.; Akhtar, T. Solid Waste Management in Saudi Arabia. Appl. Agric. Biotechol. 2016, 1, 13-26.

44. Zafar, S. Solid Waste Management in Saudi Arabia. Available online: www.ecomena.org/solid-wastemanagement-in-saudi-arabia (accessed on 2 May 2017).

45. Bereskie, T.; Haider, H.; Rodriguez, M.J.; Sadiq, R. Framework for continuous performance improvement in small drinking water systems. Sci. Total Environ. 2017, 574, 1405-1414. [CrossRef] [PubMed]

46. Christoffersen, H.; Bo Larsen, K. Economies of scale in Danish municipalities: Expenditure effects versus quality effects. Loc. Gov. Stud. 2007, 33, 77-95. [CrossRef]

47. Karthikeyan, L.; Suresh, V.M.; Krishnan, V.; Tudor, T.; Varshini, V. The Management of Hazardous Solid Waste in India: An Overview. Environments 2018, 5, 103. [CrossRef]

48. Dumlao-Tan, M.I.; Halog, A. Moving Towards a Circular Economy in Solid Waste Management: Concepts and Practices. Chapter 2 of Integrated Solid Waste Management: A Life Cycle Inventory; MPG Books Ltd.: Cornwall, UK, 2003.

(C) 2019 by the authors. Licensee MDPI, Basel, Switzerland. This article is an open access article distributed under the terms and conditions of the Creative Commons Attribution (CC BY) license (http://creativecommons.org/licenses/by/4.0/). 